\title{
Clinical considerations and key issues in the management of patients with Erdheim-Chester Disease: a seven case series
}

\author{
Roei D Mazor ${ }^{1,2}$, Mirra Manevich-Mazor ${ }^{2}$, Anat Kesler ${ }^{3}$, Orna Aizenstein $^{4}$, Iris Eshed ${ }^{5}$, Ronald Jaffe ${ }^{6}$, Yakov Pessach?
} Ilan Goldberg ${ }^{7}$, Eli Sprecher ${ }^{7}$, Iris Yaish ${ }^{8}$, Alexander Gural ${ }^{9}$, Chezi Ganzel ${ }^{10}$ and Yehuda Shoenfeld ${ }^{1 *}$

\begin{abstract}
Background: Erdheim-Chester Disease (ECD), a non Langerhans' cell histiocytosis of orphan nature and propensity for multi-systemic presentations, comprises an intricate medical challenge in terms of diagnosis, treatment and complication management.

Objectives: The objectives are to report the clinical, radiological and pathological characteristics, as well as cardinal therapeutic approaches to ECD patients and to provide clinical analyses of the medical chronicles of these complex patients.

Methods: Patients with biopsy proven ECD were audited by a multi-disciplinary team of specialists who formed a coherent timeline of all the substantial clinical events in the evolution of their patients' illness.

Results: Seven patients (five men, two women) were recruited to the study. The median age at presentation was 53 years (range: 39 to 62 years). The median follow-up time was 36 months (range: 1 to 72 months). Notable ECD involvement sites included the skeleton (seven), pituitary gland (seven), retroperitoneum (five), central nervous system (four), skin (four), lungs and pleura (four), orbits (three), heart and great vessels (three) and retinae (one). Prominent signs and symptoms were fever (seven), polyuria and polydipsia (six), ataxia and dysarthria (four), bone pain (four), exophthalmos (three), renovascular hypertension (one) and dyspnea (one). The V600E BRAF mutation was verified in three of six patients tested. Interferon-a treatment was beneficial in three of six patients treated. Vemurafenib yielded dramatic neurological improvement in a BRAF mutated patient. Infliximab facilitated pericardial effusion volume reduction. Cladribine improved cerebral blood flow originally compromised by perivenous lesions.
\end{abstract}

Conclusions: ECD is a complex, multi-systemic, clonal entity coalescing both neoplastic and inflammatory elements and strongly dependent on impaired RAS/RAF/MEK/ERK signaling.

Keywords: Erdheim Chester, BRAF, NRAS, Vemurafenib, Interferon-a, Histiocytosis

\section{Introduction}

Erdheim Chester disease (ECD) is a rare type of non Langerhans cell histiocytosis $[1,2]$. It is chiefly characterized by the migration and infiltration of lipid laden CD68(+), CD1a(-) histiocytes to various target organs resulting in the disruption of tissue architecture and fibrosis, thus causing impaired organ function and often bone pain [3]. Among different individuals, this condition may manifest

\footnotetext{
* Correspondence: shoenfel@post.tau.ac.il

${ }^{1}$ The Zabludowicz Center for Autoimmune Diseases, Sheba Medical Center, Tel Hashomer, Israel

Full list of author information is available at the end of the article
}

in a heterogeneous spectrum of severity ranging from a mild to a life threatening disease [4]. Different patients may also present with an assortment of symptoms correlating with their specific sites of infiltration. However, up to $96 \%$ of patients exhibit radiological involvement of the skeleton [5]. While ${ }^{99 \mathrm{~m}} \mathrm{Tc}$ bone scintigraphy and positron emission tomography/computed tomography (PET/CT) are commonly used in the diagnosis of ECD, bone magnetic resonance imaging (MRI) may serve as a sensitive and valuable tool in the evaluation of cancellous bone involvement [6]. Apart from the skeletal system, other sites of involvement include the central nervous system [7-11], 
heart and great vessels [12-15], lungs [16-18], kidneys and retroperitoneum [19-23], adrenal glands [24], skin [25-27], gastrointestinal tract [28-31], breast [32-34], skeletal muscle [32,35], thyroid and testis [36]. Hemophagocytosis was also documented in the context of ECD [37]. Involvements of the central nervous system (CNS) and cardiovascular systems, in particular, were reported to be associated with an overall poor prognosis [38]. This is important to emphasize since the cardiovascular manifestations of ECD are frequently overlooked [39]. Although the mean age of diagnosis among ECD patients is 55 [5], pediatric cases have been documented [40-44]. To date, the etiology of ECD remains unknown and its pathogenesis, poorly understood. Much debate has arisen relating to the clonality of ECD [45-48]. On the one hand, it is well established that ECD is a phenomenon involving a dominant Th1 immune response, suggesting a dysregulated, inflammatory mechanism [49]. On the other hand, the V600E BRAF mutation recently identified in $54 \%$ of the patients [50] necessitates a precursor cell harboring this somatic mutation and, thus, a clonal neoplastic origin. A novel approach is described by Berres et al., who suggest that ECD is an example of an 'inflammatory myeloid neoplasm' [51]. The fitting therapeutic roadmap for the ECD patient is a complex mosaic of various clinical elements [52,53]. A diverse compilation of pharmacology has been under investigation over the past years in an attempt to strike at the Achilles heel of the disease. Currently, interferon- $\alpha$ is the sole agent which has demonstrated an increase in survival and is, thus, considered the first line of treatment [14,38,54-56]. Various second line treatments exist. Anakinra, an interleukin-1 receptor antagonist is suitable for mild disease [13,40,57-59]. Infliximab, an anti TNF- $\alpha$ monoclonal antibody has shown efficacy in the treatment of the cardiovascular involvement of ECD [60]. Vemurafenib, a small molecule which inhibits the V600E mutated $B R A F$ protein, was found to induce remarkable responses among patients who harbor that mutation $[61,62]$. Finally, cladribine may be a reasonable therapeutic alternative for patients with moderate to severe disease who failed previous second line regimens [63-66]. Other treatments include various types of chemotherapeutic agents [67-70], radiation therapy [71-74], steroids [38,54,70,75], bisphosphonates [76-78] and bone marrow transplantation $[79,80]$. The prognosis of ECD is poor. Most patients suffer from progressive morbidity, which may relate to both the disease itself and its treatments. As for mortality, according to the largest series published, the one- and five-year survival rates of ECD patients are $96 \%$ and $68 \%$, respectively [38].

\section{Patients and methods}

Seven patients (five men, two women) were recruited to the study from six different medical centers in Israel
(Table 1). Of these seven patients, five are discussed in detail. Each patient was evaluated and audited according to his/her disease distribution. Patients were included in this study subsequent to meeting the following inclusion criteria: first, a pathological confirmation was obtained only after the identification of CD68(+), CD1a(-) histiocytes in a biopsy specimen harvested from a locus of clinical interest. Second, a thorough, professionally performed workup of the patient was completed. This workup must have included a detailed anamnesis and a meticulous physical examination. Laboratory investigations must have included at least one complete blood count and one full blood chemistry panel. In regards to imaging, the patient must have undergone at least one CT scan of the thorax, abdomen and pelvis and one brain MRI. Cardiac MRI was performed only in patients suspicious of cardiovascular involvement on the basis of suggestive symptoms or prior imaging. As for nuclear medicine, at least one ${ }^{99 \mathrm{~m}} \mathrm{Tc}$ bone scintigraphy or one fluorodeoxyglucose (FDG) PET scan must have been performed. Molecular analyses of the BRAF oncogene were performed in six of the seven patients using digital PCR amplification followed by sequencing of the amplified segments using either Sanger's sequencing technique or pyrosequensing, depending on the medical center in which each examination was performed.

\section{Case reports}

Patient \#1: a longstanding disease with multiple system involvement and a dramatic response to vemurafenib

A 39 year-old woman of Turkish-Iraqi descent presented in September 2007 to the emergency department with low grade fever, signs of weakness and difficulty walking due to diffuse bone pain mostly in the knees and both pectoral and pelvic girdles. Shortly before her admission the patient began experiencing alternating hot flashes and cold bouts disproportionate to the weather or clothing and suffered from frequent night sweats. Approximately six months prior to this incident, fatigue and leg pain slowly developed. The pain originally began as a tingling sensation, accompanied by paresthesia. It had escalated over several months and progressed to fully fledged bone pain. At the time of presentation, the pain was described as initiating at rest and constant, occasionally accompanied by episodes of fever. The patient was admitted for several consecutive hospitalizations. Upon inspection of her face, both exophthalmos and yellowish peri-orbital xanthelasmae-like lesions were apparent. The remainder of her physical examination was unremarkable, without deformation or bony swelling and without neurological deficits. It is noteworthy that the patient was polydypsic and polyuric for approximately five years prior to the onset of bone pain, consuming and excreting up to 12 liters of water per day. 
Table 1 Characteristics of the seven ECD patients

\begin{tabular}{|c|c|c|c|c|c|c|c|c|c|c|c|c|}
\hline$\#$ & Age & Sex & Presenting sign/symptom & Disease involvement sites & BS & CT & $\mathrm{PET} / \mathrm{CT}$ & $\begin{array}{l}\text { Brain } \\
\text { MRI }\end{array}$ & $\begin{array}{l}\text { Heart } \\
\text { MRI }\end{array}$ & Treatment roadmap & $\begin{array}{l}\text { Notable responses } \\
\text { and timeframe }\end{array}$ & BRAF status \\
\hline 1 & 39 & $\mathrm{~F}$ & Bone pain & STN, CNS, PIT, ROS, CUT, RP, PLM, RTN & + & + & + & + & - & $\begin{array}{l}\mathrm{STR} \rightarrow \mathrm{VB} \rightarrow \mathrm{IFNa} \rightarrow \mathrm{IFNa}+ \\
\mathrm{VB} \rightarrow \mathrm{ANK} \rightarrow \mathrm{CLD} \rightarrow \mathrm{VMR}\end{array}$ & $\begin{array}{l}\text { VMR: marked neurological } \\
\text { improvement in } 3 \mathrm{w}\end{array}$ & + \\
\hline 2 & 50 & M & Skin lesions and bone pain & STN, CNS, PIT, CUT, RP, ADR, LYM & + & + & - & + & - & CLD & $\begin{array}{l}\text { CLD: regression of intracranial } \\
\text { perivenous lesion and neurological } \\
\text { stabilization, gradually over } 13 \mathrm{~m}\end{array}$ & - \\
\hline 3 & 62 & $\mathrm{~F}$ & Bone pain & STN, PIT, ROS, CUT, PLM, CV & + & + & + & + & + & $\begin{array}{l}\mathrm{STR} \rightarrow \mathrm{MTX}+\mathrm{STR} \rightarrow \mathrm{IFNa}+ \\
\mathrm{VB} \rightarrow \mathrm{VB} \rightarrow \mathrm{INX}+\mathrm{MTX}\end{array}$ & $\begin{array}{l}\text { INX + MTX - reduction in pericardial } \\
\text { effusion volume over a } 2 \mathrm{~m} \text { period }\end{array}$ & - \\
\hline 4 & 55 & M & Ataxia and dysarthria & STN, CNS, PIT, MNG, RP & - & + & + & + & - & IFNa & - & UNK \\
\hline 5 & 53 & M & Ataxia and dysarthria & STN, CNS, PIT, MNG & + & + & + & + & - & $\mathrm{STR} \rightarrow \mathrm{VB} \rightarrow \mathrm{plFN} \rightarrow \mathrm{CLD}$ & - & - \\
\hline 6 & 49 & M & Abdominal pain & STN, PIT, ROS, RP, PLM, CV, Gl & + & + & + & + & + & $\begin{array}{l}\mathrm{STR}+\mathrm{VB}+\mathrm{IFNa} \rightarrow \mathrm{VB}+ \\
\mathrm{IFNa} \rightarrow \mathrm{IFNa} \rightarrow \mathrm{pIFNa} \rightarrow \\
\mathrm{VMR} \rightarrow \mathrm{pIFNa}\end{array}$ & $\begin{array}{l}\text { VMR: marked skin toxicity even at } \\
\text { low doses }\end{array}$ & + \\
\hline 7 & 58 & M & Polyuria, polydipsia and HTN & STN, PIT, CUT, RP, PLM, CV & + & + & + & + & + & IFNa & $\begin{array}{l}\text { IFNa: Normalization of constitutional } \\
\text { symptoms over a } 6 \mathrm{~m} \text { period }\end{array}$ & + \\
\hline
\end{tabular}

ADR, adrenal glands; ANK, anakinra; BS, $99 \mathrm{~m} T \mathrm{Tc}$ bone scintigraphy; CLD, cladribine; CNS, central nervous system; CT, computed tomography; CUT, cutaneous involvement; $C V$, cardiovascular system; $F$, female; Gl, gastrointestinal tract; HTN, hypertension; IFNa; interferon alpha; pIFNa, pegylated interferon alpha; INX, infliximab; LYM, lymph nodes, m, month; M, male; MNG, meninges; MRI, magnetic resonance imaging; MTX, unknown; VB, vinblastine; VMR, vemurafenib; w, weeks. 
Despite this, a diagnosis of central diabetes insipidus was established and treatment with intranasal desmopressin initiated only upon hospitalization, presumably due to the patient's adjustment to the gradual changes in water metabolism over the years. Apart from her known iron deficiency anemia, laboratory studies revealed increased levels of C-reactive protein (CRP: $70 \mathrm{mg} / \mathrm{L}$ ) and elevated erythrocyte sedimentation rate (ESR: $72 \mathrm{~mm} /$ hour). A broad panel of immunologic studies, including rheumatoid factor (RF) and anti-nuclear antibodies was unremarkable. Negative blood and urine cultures ruled out an infectious etiology. Protein electrophoresis (PEP) yielded no monoclonal spike and the oncological markers were found to be within normal limits. Further investigations included radiography, which revealed bilateral sclerotic changes in the femoral and tibial bones and electromyography, which demonstrated normal muscle and nerve functionality. A subsequent ${ }^{99 \mathrm{~m}}$ Tc bone scintigraphy demonstrated increased tracer uptake in the superior aspect of both orbits, the central sphenoidal region, left humeral head, right femoral greater trochanter and lateral superior aspect of the left iliac crest as well as diffuse, symmetric, bilateral increased tracer uptake in the femurs and tibiae enveloping both knees (Figure 1A). A CT of the femurs and tibiae exhibited an irregular osseous texture demonstrating bones riddled with mixed patchy lesions of sclerotic and lytic nature. This was suggestive of either a metabolic, malignant or granulomatous process. An additional CT of the thorax, abdomen and pelvis revealed congestion of both renal sinuses with slightly distended ureters (Figure 2A). CT and later MRI of the brain revealed bilateral retro-orbital nodular lesions (Figure 3A), diffuse thickening and tortuosity of the optic nerves, enlargement of both lacrimal glands and soft tissue fullness of the sphenoid sinus (Figure 3C). An MRI dedicated to the pituitary revealed no deviation from the normal anatomy. Over the two week period between two consecutive hospitalizations papilledema developed, accompanied by headaches, blurred vision and nausea. A lumbar puncture revealed an increased opening pressure of $44 \mathrm{cmH}_{2} \mathrm{O}$. Treatment with acetazolamide ( $250 \mathrm{mg} \mathrm{X3}$ daily) was initiated, the increased intracranial pressure normalized and related symptoms abated. Biopsies were obtained from the tibial bone marrow and from a lacrimal gland. A microscopic examination of the tibial biopsy revealed bony trabeculae separated by a xanthomatous, diffuse spindle cell macrophage population with few interspersed giant cells (Figure 4A). The spindle cells stained relatively uniformly for the presence of CD163, and in a more patchy fashion but quite strongly for factor XIIIa (Figure 4C), surface staining for CD14 and granular intense staining for CD68 (Figure 4B). CD1a and S-100 staining were globally negative (Figure 4D) except for one focus of S-100(+) cells, suggesting infiltration of the marrow with Langerhans cells. Overall, these findings were most consistent with a diagnosis of ECD with a component of Langerhans cell histiocytosis. Over the five years pursuant to her diagnosis on May 2007, the patient was treated with several treatment protocols. At first, steroids (prednisone, $60 \mathrm{mg} /$ day) provided a temporary relief - a marked decrease in bone pain, decrease in CRP levels and normalization of fever. Two months later vinblastine $\left(6 \mathrm{mg} / \mathrm{m}^{2} /\right.$ week $)$ was introduced

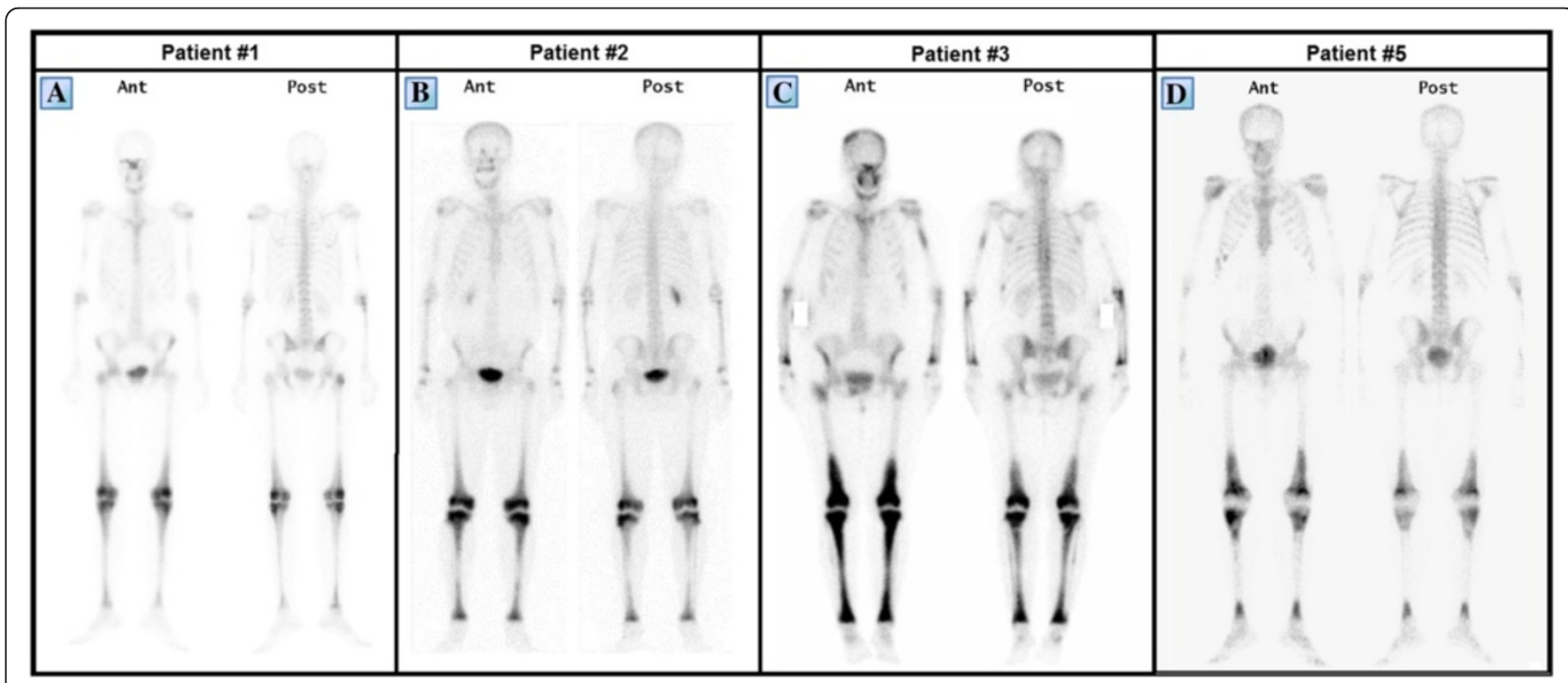

Figure $1{ }^{99 \mathrm{~m}} \mathrm{Tc}$ bone scintigraphs of patients \#1 (A), \#2 (B), \#3 (C) and \#5 (D) taken prior to diagnosis. Note the characteristic bilateral symmetric pattern of increased tracer uptake, particularly involving the femoral and tibial long bones and the periarticular regions of the knees. Despite an obvious variability in the degree of tracer uptake among patients in these series, the intensity of tracer uptake did not necessarily correlate with the degree of bone pain at the time of presentation. 

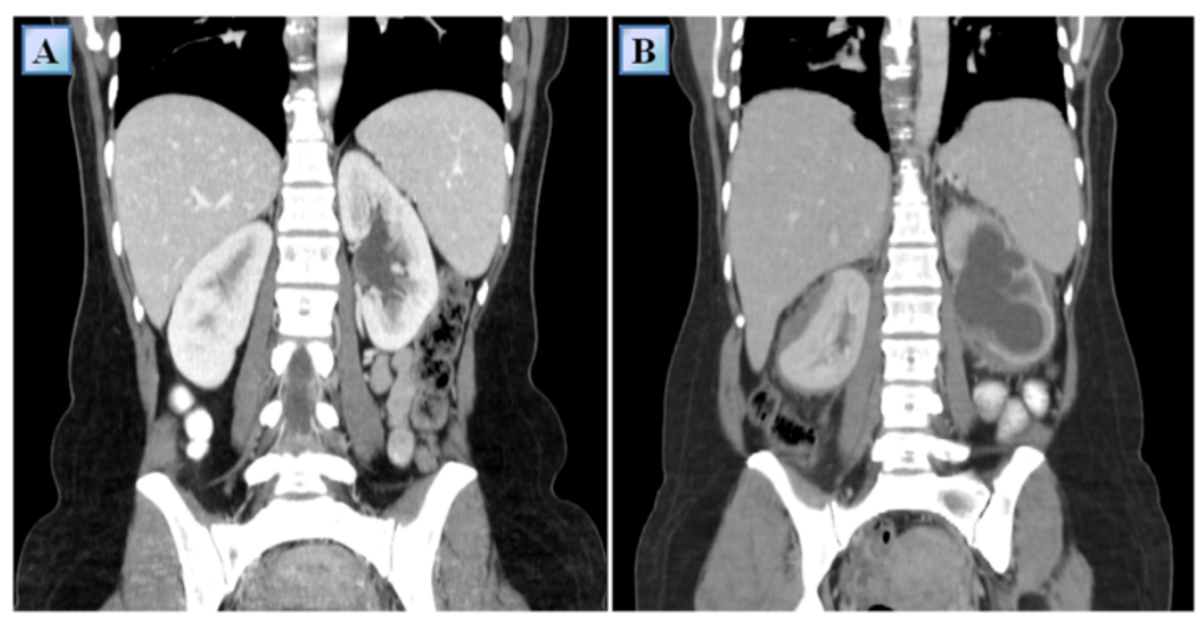

Figure 2 Coronal reformatted contrast enhanced computed tomography images of patient \#1, obtained at the time of the diagnosis (A) and 4.5 years after the diagnosis (B). The latter reveals severe hydronephrosis and marked cortical thinning of the left kidney and a peri-renal mass compressing the right kidney. Also, note the fine bilateral peri-renal infiltrate forming a 'hairy kidney' appearance.

as a steroid sparing agent. This protocol failed to evoke a favorable long lasting response and was substituted for treatment with interferon- $\alpha$. Since then, interferon- $\alpha$ has served as the primary therapeutic agent administered at dosages as low as $3 \times 10^{6}$ IU X 3 times weekly and as high as $6 \times 10^{6}$ IU X 5 times weekly. Initially, interferon- $\alpha$ was administered as a single agent. Later on, it was complemented by vinblastine ( $8 \mathrm{mg} / 1$ to 4 months) and by pamidronic acid (60 mg/1 to 3 months) in order to better control the lytic lesions. It is noteworthy that this patient continued to deteriorate neurologically even at the highest doses of interferon- $\alpha$ administered $\left(6 \times 10^{6}\right.$ IU X 5 times weekly). However, the addition of vinblastine to this regimen succeeded in stabilizing the patient clinically and allowed for a gradual decrease in the dosage of interferon$\alpha$ to a maintenance dose of $6 \times 10^{6}$ IU X 2 times weekly over a two year period. Three years after the diagnosis of ECD, a four-month trial of anakinra (100 $\mathrm{mg} /$ day) was attempted, mainly due to multifocal disease progression. However, this agent yielded unsatisfactory results. This attempt was followed by a five-month trial of cladribine $(0.14 \mathrm{mg} / \mathrm{kg} /$ day for five consecutive days, every four weeks), a drug which yielded no apparent benefit to the patient and was very poorly tolerated. By this time, the patient's neurological symptoms, vis-à-vis her lingual and motor capabilities, had deteriorated greatly once again. She was markedly dysarthric and confined to a wheelchair. Consequently, a biopsy obtained from the peri-renal mass was attempted and found to contain ECD histiocytes which harbor the V600E BRAF mutation. After receiving proper counseling and signing an informed consent, treatment with vemurafenib $(1,920 \mathrm{mg} /$ day later tapered to $960 \mathrm{mg} /$ day) was initiated with no less than a spectacular improvement. After two weeks of treatment the patient began to exhibit clinical improvement. Ultimately, following treatment with this agent, the patient regained her ability to walk distances of up to 500 meters and recovered her ability to speak fluently.

\section{Patient \#1 - clinical analysis}

Overall, the patient's tolerance and response to treatment were the prime variables taken into consideration in the formulation of her therapeutic roadmap. Since the initial presentation of symptoms and throughout the different therapeutic lines, several significant radiological and clinical events had occurred.

First and foremost, following treatment with interferon$\alpha$, the patient experienced complete resolution of the bone pain. Nevertheless, consecutive CT and PET/CT scans revealed deterioration of the osteosclerotic processes in the long bones as well as intense bilateral periarticular tracer uptake indicative of an active disease (Figure 5A,B). This was further substantiated by a gradual increase in bone density as shown on annual DXA (duel energy $x$-ray absorptiometry) assays aimed at assessing the bone density of the femurs, pelvis and spine.

Second, one year following diagnosis, the retro-orbital lesions achieved maximal size (Figure 3A), with one lesion protruding extraconaly through the inferior orbital fissure causing inferior displacement of the orbit. The severe clinical progression necessitated the initiation of an aggressive combination treatment protocol comprising high dose interferon- $\alpha\left(9 \times 10^{6}\right.$ IU X 3 times weekly), vinblastine $(8 \mathrm{mg} / \mathrm{month})$ and pamidronic acid $(60 \mathrm{mg} /$ month). This treatment protocol resulted in marked regression of the retro-orbital lesions and was clinically evident by normalization of the exophthalmos and improvement of visual acuity (Figure 3B). The treatment 


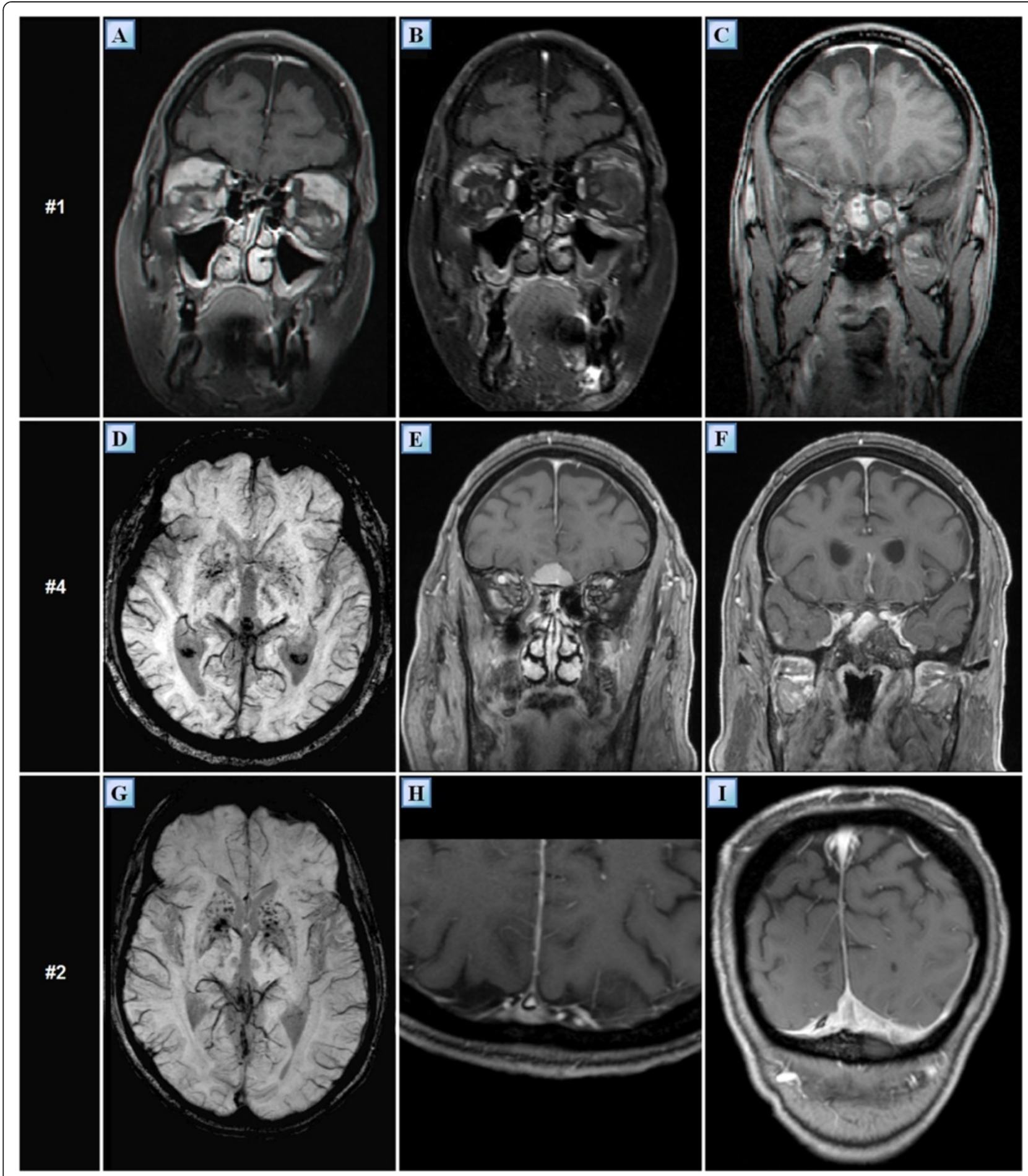

Figure 3 Various intracranial MRI findings of patients \#1, \#2 and \#4. Coronal T1 weighted, gadolinium enhanced MR images of the retro-bulbar regions of patient \#1 one year following diagnosis (A) and 4.5 years after diagnosis (B). The former (A) demonstrates bilateral nodular masses located at the superior lateral aspect of the retro-orbit. These masses involve both the lacrimal glands and superior rectus muscles and undergo heterogeneous enhancement following gadolinium administration. The latter (B) demonstrates a marked reduction in the size of these lesions, presumably due to treatment with interferon-a. (C) Coronal T1 weighted, gadolinium enhanced MR image of patient \#1 showing mucosal thickening in the sphenoidal sinus as well as soft tissue fullness which undergoes enhancement following gadolinium administration. This finding is also apparent in patient \#4 (F), who also exhibits an extra axial enhancing lesion situated in the vicinity of the planum sphenoidale (E). In SWI sequence, both patients \#4 (D) and \#2 (G) exhibit multiple punctate hypointensities in the basal ganglia. These patterns are not typical for senile calcifications. Patient \#2 also exhibits infiltrative enhancing tissue which narrows the transverse left sinus, adjacent to the falx and tentorium (I). The same tissue is seen displacing the superior sagittal sinus $\mathbf{( H )}$. MR, magnetic resonance; SWI, susceptibility weighted imaging. 


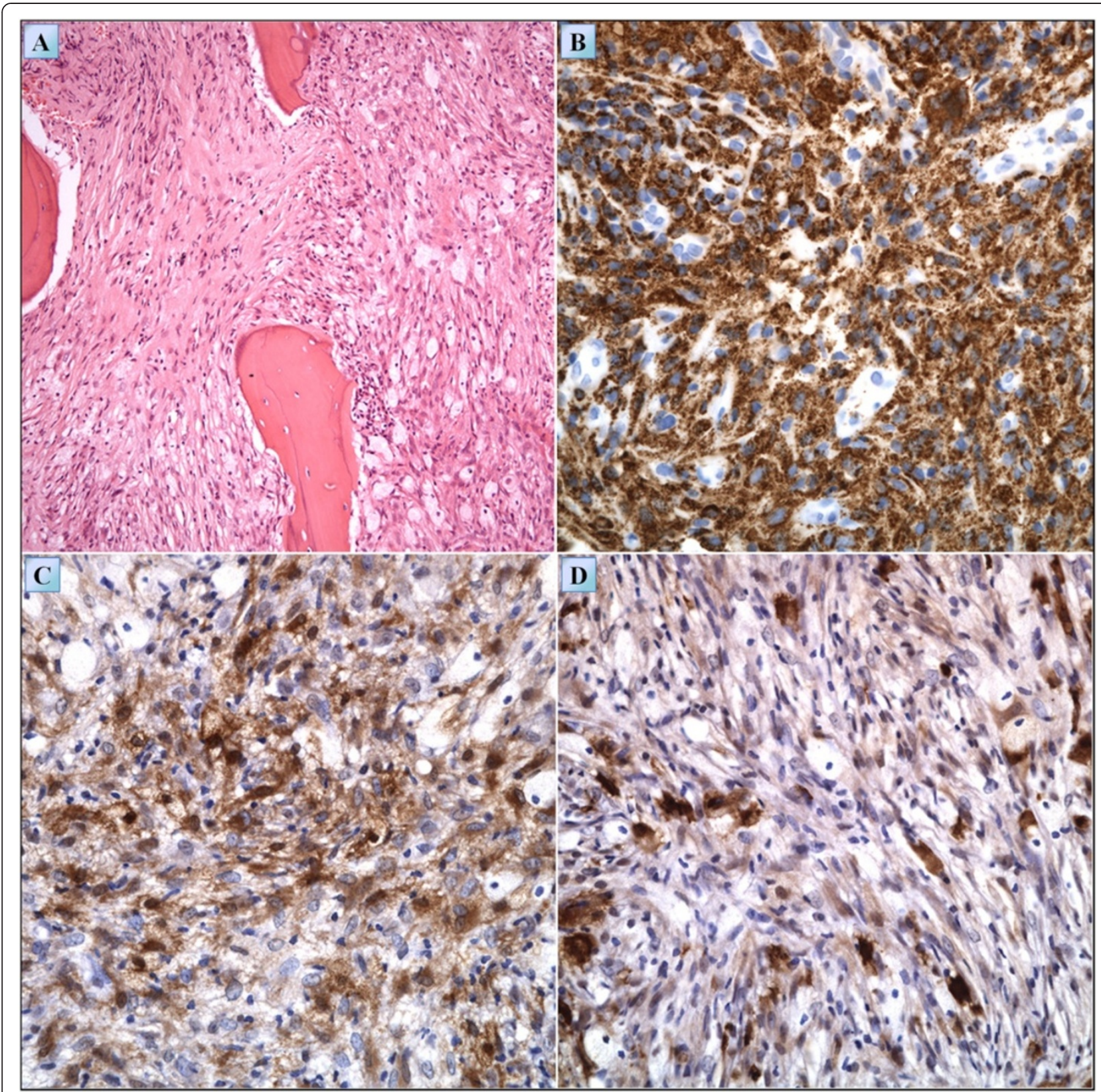

Figure 4 Histological sample from the tibia of patient \#1. (A) H\&E. Bony trabeculae separated by fibrosis and sheets of foamy macrophages. (B) Histiocytes demonstrating intense granular staining for CD68. (C) Histiocytes demonstrating patchy staining for factor XIlla. (D) S-100 protein staining of the biopsy specimen.

also resulted in partial regression of the soft tissue fullness that originally developed inside the sphenoidal sinus. However, in parallel to the regression of the lesions mentioned above, new lesions have begun developing in concert with the interferon- $\alpha$ treatment. These new lesions appeared to be bilateral and to involve the cerebellar peri-dentate region, the middle cerebellar peduncles and the white matter of the pons (Figure 6A-C). Three years after her diagnosis, the patient's ataxia and dysarthria progressed markedly.
Third, frequent fundoscopies were performed due to the patient's tendency to develop papilledema in conjunction with episodes of increased intracranial pressure. Four years following diagnosis, new sub-choroidal lesions involving the macula densa appeared on fundoscopy of both eyes (Figure 7A-B). These findings were even more visible on red free imaging produced by a blue wavelength confocal scanning laser ophthalmoscope (Figure 7C-D). These findings proved to be stable on a neuro-ophthalmological follow up performed two years 


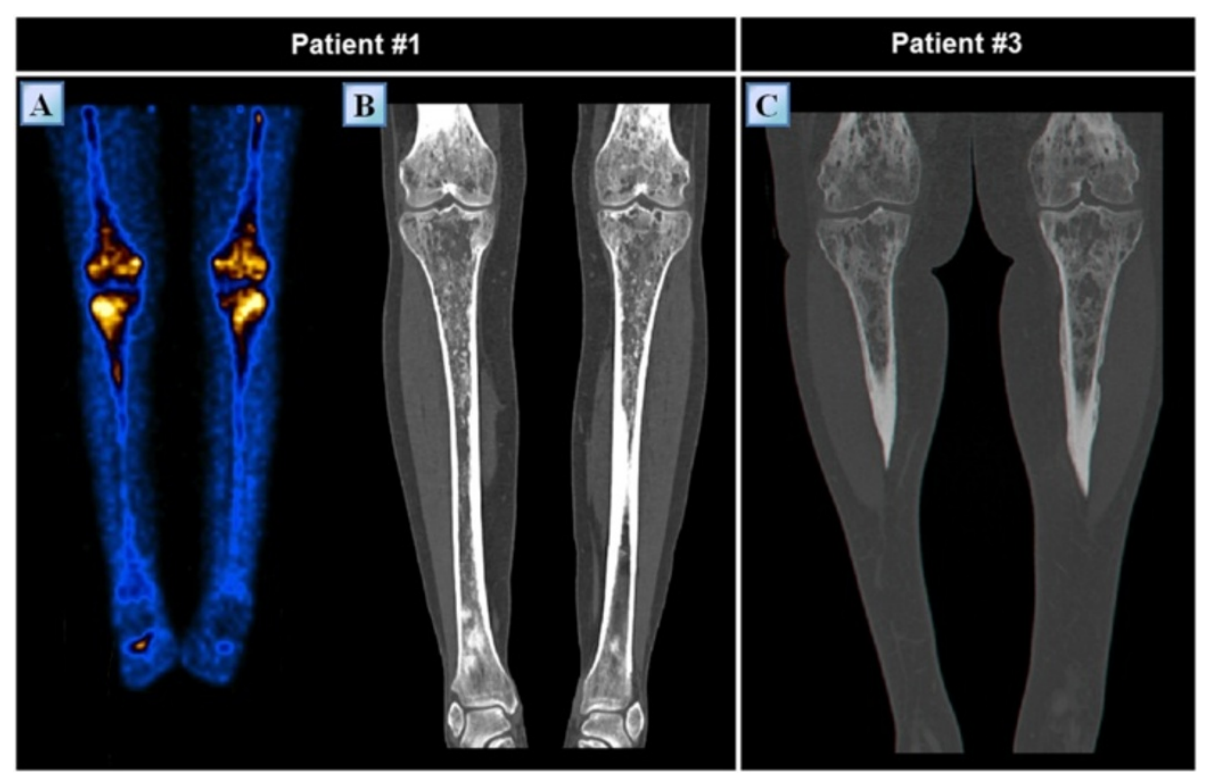

Figure 5 PET and CT findings of the lower limbs of patients \#1 and \#3 (A) Positron emission tomography showing symmetric, bilateral, abnormally increased intra-medullary uptake of fluorodeoxyglucose in the femurs and tibiae of patient \#1 approximately 4.5 years following diagnosis. (B) Computed tomography of the femurs and tibiae of patient \#1 at the time of diagnosis, exhibiting periostitis as well as diffuse, irregular intra-medullary sclerosis. These bones are riddled with mixed patchy lesions of sclerotic and lytic nature encased in a markedly thickened cortex. (C) Similar findings can be observed in the computed tomography of patient \#3.

following their discovery. Thus, the initial visual field disturbances of patient \#1 were attributed to increased intracranial pressure while those that appeared later, were attributed to these subchoroidal lesions.

Fourth, despite aggressive treatment, over the five-year period since diagnosis infiltration of the retroperitoneum had occurred with formation of a mild, bilateral 'hairy kidney' appearance on CT (Figure 2B). The left kidney underwent severe hydronephrosis with marked cortical thinning and the right kidney became compressed by a peri-renal mass. It is noteworthy that this mass was characterized by an increased tracer uptake on PET/CT. Globally, at the time of follow up, renal function is preserved with creatinine levels within normal limits.

Overall, a five-year follow up reveals favorable responses to treatment with interferon- $\alpha$ in terms of bone pain amelioration and regression of the retro-orbital lesions (Figure 3B). However, this agent had little effect on the retroperitoneal, central nervous system and ophthalmological involvements of the disease. Ultimately and most importantly, the patient exhibited dramatic improvement in neurological function following her treatment with vemurafenib.

\section{Patient \#2: a cutaneous presentation with intracranial} perivenous involvement responding to cladribine

A 50-year-old man of Iraqi descent presented to an outpatient dermatology clinic in September 2010, complaining of asymptomatic skin lesions which had been recurring and remitting over the past seven years (Figure 8B). Upon an elaborated history, the patient disclosed suffering from mild lower limb pain, loss of libido and increased thirst and urination for the past seven years, as well. On examination, 10 red-yellow papules, 4 to $8 \mathrm{~mm}$ in size, were observed over his trunk and extremities. Laboratory findings revealed decreased levels of testosterone ( $3 \mathrm{nmol} / \mathrm{L})$, lutenizing hormone $(\mathrm{LH})(0.3 \mathrm{mIU} / \mathrm{mL})$ and follicle-stimulating hormone $(\mathrm{FSH})(0.4 \mathrm{mIU} / \mathrm{mL})$. A 24 hour urine collection concluded in increased urine volume $(3.2 \mathrm{~L})$ and decreased urine osmolality. These findings led to the diagnosis of central diabetes insipidus and hypogonadotropic hypogonadism; thus, the patient initiated treatment with intranasal desmopressin and monthly intramuscular injections of choriogonadotropin alfa. Other laboratory tests including a complete blood count, thyroid hormones, lipid profile, viral serologies, protein electrophoresis, purified protein derivative (PPD), angiotensin-converting enzyme (ACE) and tumor markers were without pathological findings. Several imaging studies were conducted. Plain radiography demonstrated marked osteosclerosis of the tibiae and fibulae. A ${ }^{99 m}$ Tc bone scintigraphy revealed intense symmetric bilateral uptake of tracer in the diametaphyseal regions of the distal femurs and proximal tibiae (Figure 1B). A brain MRI demonstrated thickening of the pituitary stalk and several cluster-like nodular enhancing lesions involving the left cerebellum in close proximity to the fourth ventricle (Figure 6D,E). Also, multiple 


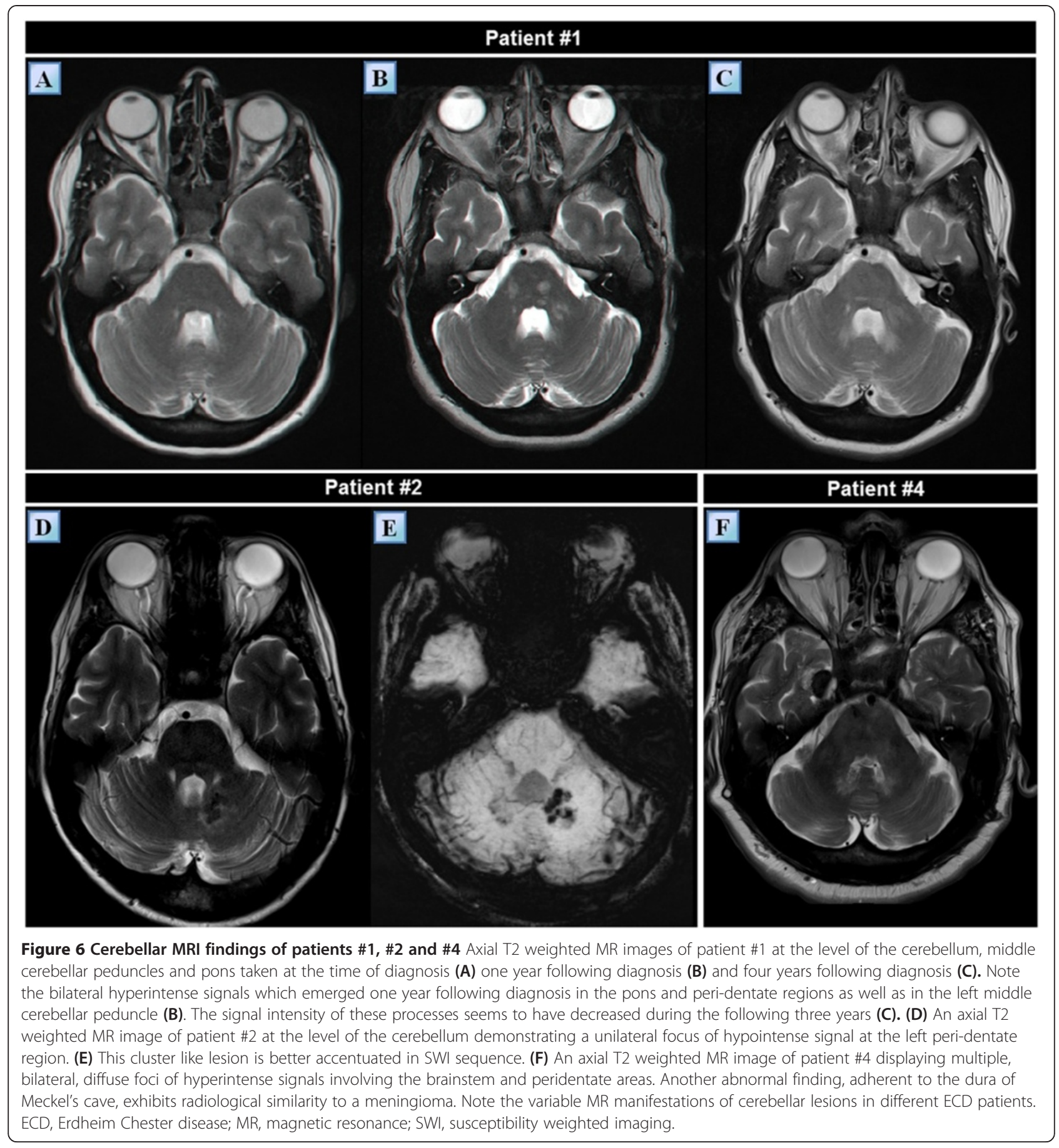

punctate hypointensities were noted in the basal ganglia in SWI sequence (Figure 3G). This pattern is not typical of senile calcifications. The most prominent finding in this patient's workup was that of intracranial soft tissue infiltrating posterior to the confluence of sinuses and sheathing the superior sagittal and left transverse sinus (Figure 3H-I). A whole body CT scan showed infiltration of the perirenal fat and bilateral enlargement of the adrenal glands. Three biopsies were eventually conducted: one of a skin lesion and two bone marrow biopsies. Surprisingly, both of the bone marrow biopsies exhibited normal bone marrow. However, the skin biopsy revealed histiocytes of varied morphology embedded in a lymphocytic infiltrate. The histiocytes stained positive for CD68 and negative for CD1a and Factor XIIIa. Electron microscopy of the specimen showed clusters of lipid droplets, with no evidence of Birbeck granules. These pathological findings were supportive of the diagnosis of ECD. Since 


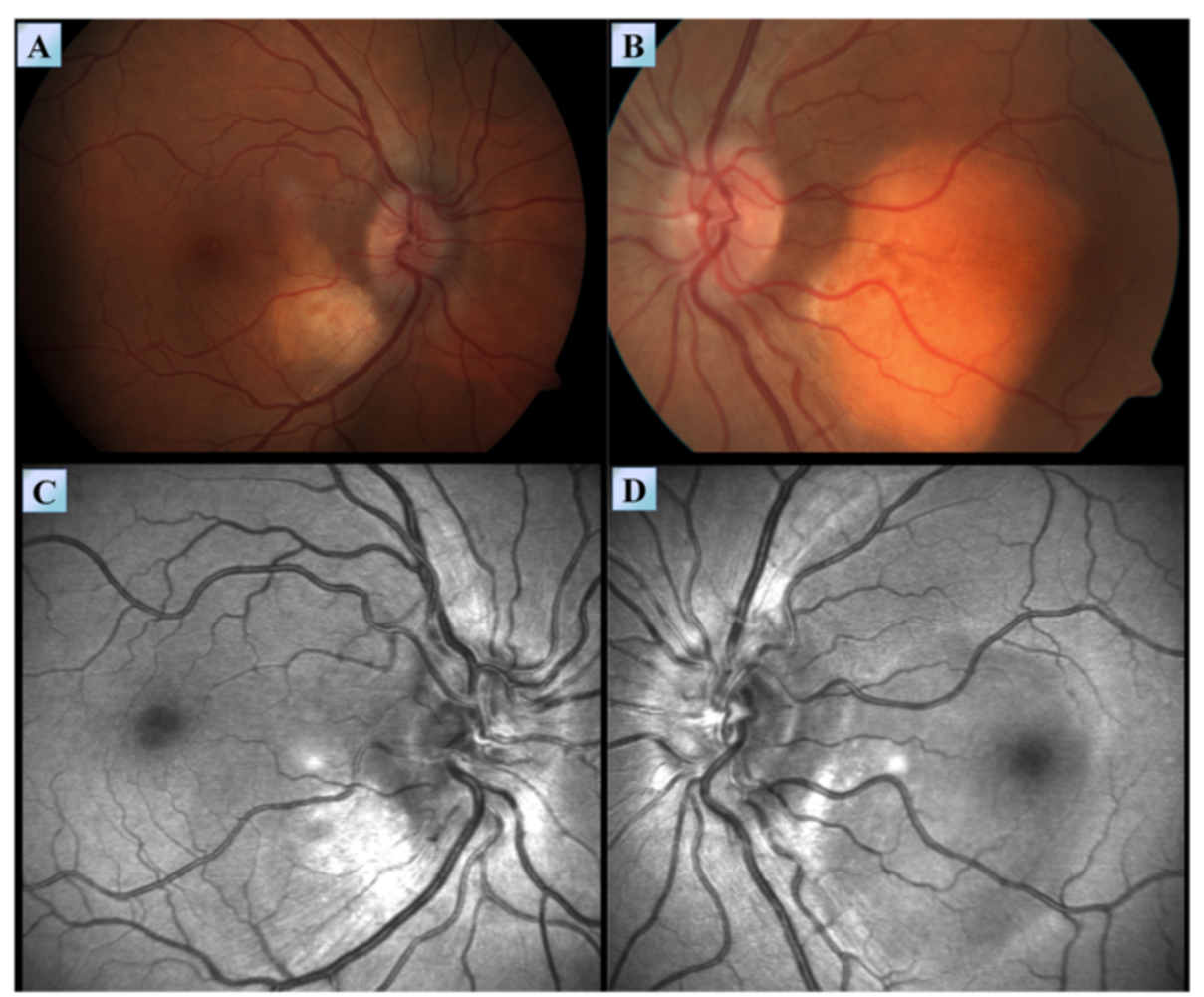

Figure 7 Fundoscopy of patient \#1. Fundoscopy images of the right (A) and left (B) eyes of patient \#1, demonstrating sub choroidal lesions involving the macula densa. (C,D) Red free imaging produced by a blue wavelength confocal scanning laser ophthalmoscope demonstrating the extent of these lesions in the right (C) and left (D) eyes.

his diagnosis in October 2010, the patient deteriorated on several occasions, exhibiting a repertoire of signs and symptoms. Among them were both constitutional and neurological symptoms. The various emerging phenomena included episodes of increased intracranial pressure with papilledema, ataxia, dysarthria, pathological crying and laughing, hyper-reflexia and nystagmus. The variety of these symptoms prompted a more thorough evaluation of cerebral blood flow. Both CT venography and later MR venography demonstrated attenuated flow in the superior sagittal sinus due to external compression on the vessel, displacing it from the skull. Also, a complete collapse of
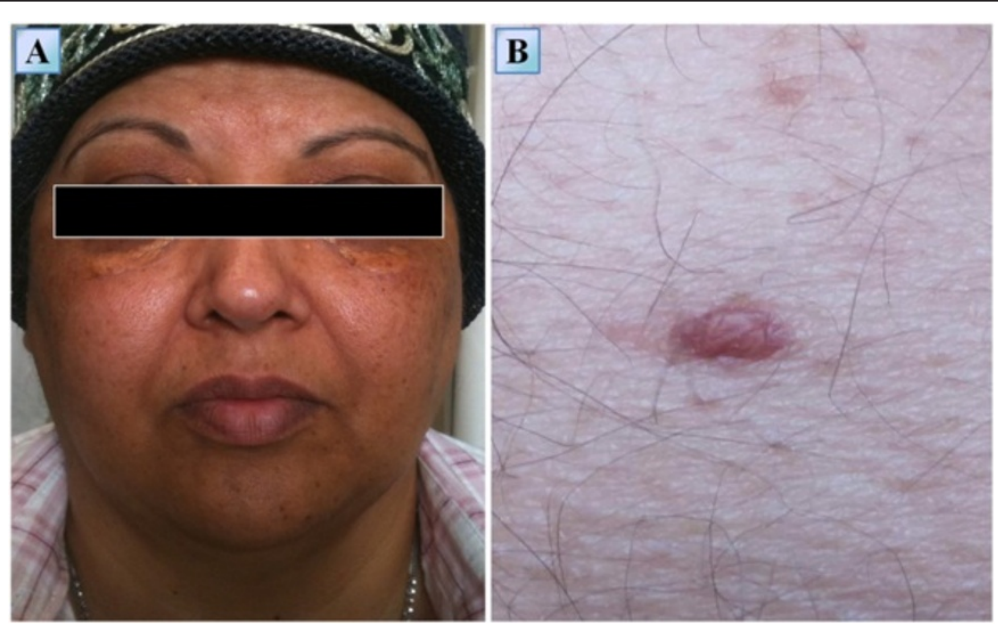

Figure 8 Skin lesions of patients \#2 and \#3. (A) Yellowish periorbital xanthelasma-like lesions in patient \#3. (B) A red yellow papule, $8 \mathrm{~mm}$ in size, over the right flank of patient \#2. 
the left transverse sinus was noted. Over the three years following the diagnosis the patient was treated with monthly four to five day courses of cladribine IV, administered intravenously at dosages of 4.5 to $4.8 \mathrm{mg}$ daily $(0.07 \mathrm{mg}$ per $\mathrm{kg}$ of body weight daily). The patient received a total of 13 courses of cladribine, which resulted in a significant improvement in his fatigue and weakness. In addition, a decrease in the episodes of papilledema and stabilization of his neurological symptoms were noted along with an evident radiological decrease in the amount of infiltrative tissue compressing the superior sagittal sinus.

\section{Patient \#2 - clinical analysis}

Several key issues should be addressed in the analysis of this patient. First, this patient exemplifies how elusive the diagnosis of ECD can be. He originally sought medical attention in an outpatient clinic to investigate his recurring dermatological lesions. A thorough workup which originated in a detailed history performed by his physicians succeeded to lift the veil off the relatively subtle symptoms that were evident in the initial phases of his disease and to associate them with his skin lesions.

Second, in this particular case, an extra-axial, perivascular intracranial process appears to impair the cerebral blood flow, causing both chronic indolent damage as well as acute flare-ups of increased intracranial pressure. It may very well be that this patient's neurological symptoms, originate both from global oxygen deprivation as well as focal disease-associated lesions. This is evident due to the nature of this patient's symptoms, as he exhibits signs of upper motor neuron impairment and episodes of increased intracranial pressure alongside pseudobulbar and cerebellar syndromes. Additionally, treatment induced lesion regression seems to slightly alleviate and stabilize the global neurological impairment while the focal deficits remain unchanged.

Third, one must consider that several biopsies may be needed to harvest a satisfactory specimen. Thus, a negative biopsy should not exclude a working diagnosis of ECD in otherwise highly suggestive settings.

Finally, this patient received prolonged treatment with lower doses of cladribine in an attempt to control his CNS involvement. Although considered an advanced line treatment in ECD, this treatment strategy appears to have resolved this patient's constitutional symptoms and caused regression of the lesions sheathing his intracranial vasculature.

\section{Patient \#3: a case of severe cardiovascular involvement stabilized by treatment with infliximab}

A 55-year-old woman of Algerian descent presented to our medical center in August 2008 with a chief complaint of worsening bone pain. She began suffering from a mild degree of diffuse bone pain 13 years ago. The pain was described as constant and as affecting her lumbar spine, knees, pelvic bones and feet. The pain was managed rather well until her time of presentation using non-steroidal anti-inflammatory drugs. At the time of presentation, the pain had intensified to a degree which prevented her to stand from a sitting position. The patient had a past medical history of diabetes insipidus for which she was diagnosed 12 years prior to her current presentation and also suffered from recurrent urinary tract infections. Her physical examination was unremarkable aside from periorbital xanthelasma-like lesions (Figure 8A). Abnormal laboratory findings included a microcytic iron deficiency anemia (hemoglobin: $11 \mathrm{~g} / \mathrm{dL}$, MCV: $77.5 \mathrm{fL}$, iron: $19 \mu \mathrm{g} / \mathrm{dL}$ ) and an elevated ESR $(98 \mathrm{~mm} / \mathrm{hr}$ ). Both protein electrophoresis and tumor markers were without pathological findings. A radiograph of the lower limbs was obtained and demonstrated bilateral involvement of the femurs and tibiae with cortical and periosteal thickening accompanied by a mixture of lytic and sclerotic lesions. These findings were even more apparent on CT (Figure 5C). A ${ }^{99 \mathrm{~m}} \mathrm{Tc}$ bone scintigraphy revealed a multifocal bone disease characterized by bilateral, symmetric increased tracer uptake involving both tibiae, distal femurs and iliac bones. Also, an asymmetric increased tracer uptake was noted in both of the upper limbs, favoring the right humerus, radius and ulna (Figure 1C). A CT guided biopsy of the right femur was performed. The specimen included cores of long bone showing focal fibrosis, foamy histiocytic infiltrate, inflammatory cells, giant cells and reactive cortical sclerosis. The histiocytes described were found to be CD68 positive and CD1a negative, a histological picture compatible with ECD. After her diagnosis was established in December 2009, the patient was treated with prednisone at an initial dosage of $60 \mathrm{mg} /$ day which underwent gradual tapering to $5 \mathrm{mg} / \mathrm{d}$ over a period of one year. Five months after the initiation of prednisone, methotrexate was introduced at escalating dosages of 10 to $25 \mathrm{mg} /$ week. This treatment protocol was successful in generating a transient decrease in bone pain which lasted for two years. However, during that period of time, the patient began experiencing extraskeletal symptoms: alternating hot flashes and cold bouts, blurred vision, headaches, nausea and vomiting. Last but not least, the patient's most prominent complaint was dyspnea, as she suffered from frequent episodes of shortness of breath following even the slightest of physical efforts, rendering her unable to walk more than 100 meters. Assessment of the patient's CNS included a brain MRI which was without pathological findings. The patient's cardio-pulmonary evaluation included several echocardiography studies which revealed recurrent pericardial effusions of moderate to large proportions with associated fibrin. Contrast enhanced CT of 
the chest demonstrated periaortic infiltration ('coated aorta') of the aortic root as well as infiltration of the mediastinum adjacent to the right atrium and also confirmed the existence of a small loculated pleural effusion. In addition to the known pericardial effusion, gadolinium enhanced cardiac gated MRI revealed thickening of the pericardium, thickening of the wall of the ascending aorta (of up to $10 \mathrm{~mm}$ ) and several lesions encasing the right atrium, right coronary artery and superior vena cava. These findings were also apparent on a whole body PET/ CT scan which demonstrated increased tracer uptake in the lesions encasing the great vessels as well as in the osseous foci consistent with the former ${ }^{99 \mathrm{~m}} \mathrm{Tc}$ bone scintigraphy. Due to the multifocal progression of her disease, the patient was started on a combination therapy regimen of interferon- $\alpha\left(3 \times 10^{6}\right.$ IU X2 to $3 /$ week $)$ and vinblastine $\left(6 \mathrm{mg} / \mathrm{m}^{2} /\right.$ week). However, this regimen was tolerated very poorly by the patient, as she became severely neutropenic with an absolute neutrophil count of less than 500 cells $/ \mu \mathrm{L}$. The dual interferon- $\alpha$ - vinblastine regimen was consequently stopped after four weeks of treatment and replaced with vinblastine as a single agent regimen at a dosage of 6 to $8 \mathrm{mg} / \mathrm{m}^{2} /$ week. Nevertheless, even this treatment was poorly tolerated and, thus, was stopped following an additional eight weeks of therapy. In parallel, the patient was tested for the V600E BRAF mutation and was found to be negative. Ultimately, a combination therapy regimen of infliximab $(5 \mathrm{mg} / \mathrm{kg} / 6$ weeks $)$ and methotrexate $(20 \mathrm{mg} /$ week) was initiated. Following six courses of treatment the patient improved clinically, with a notable decrease in the frequency and intensity of her pain, nausea and dyspnea. A marked reduction in the proportion of the pericardial effusion was noted on both echocardiography and computed tomography. However, despite treatment, the mediastinal lesions were found to be metabolically active on $\mathrm{PET} / \mathrm{CT}$ and no reduction in their size was evident on CT. Most interestingly, this treatment resulted in better control of the patient's diabetes insipidus, necessitating a decrease in the dosage of desmopressin.

\section{Patient \#3 - clinical analysis}

This patient, who suffers from ECD with a prominent cardiovascular component, presents several medically noteworthy insights. First, recurrent, moderate to large pericardial effusions comprise a worrisome medical phenomenon. These effusions raise questions regarding the potential future compromise of cardiac function in the face of rapid effusion volume fluctuations. Therefore, we recommend that ECD patients with substantial pericardial effusions should be monitored frequently using echocardiography and assessed for potential pericardiocentesis should significant cardiac compromise occur. The architecture of the mediastinal lesions, their size and location, are important variables when considering invasive interventions. In patients with extensive cardiovascular involvement, cardiac MRI may serve as the modality of choice in monitoring their complex mediastinal anatomy [12]. Overall, ECD associated encasement of the cardiac and/or mediastinal blood vessels should be monitored with caution for potential signs of stenosis. For example, in this patient, the superior vena cava and right coronary artery are involved and, thus, a high index of suspicion should remain with respect to potential emergencies involving these vessels. Compromised flow in the superior vena cava (vis-à-vis the superior vena cava syndrome) could cause both cerebral and vocal cord edema, manifesting as hoarseness and facial edema alongside superficial venous distention on the neck and upper trunk. In this patient, treatment with infliximab succeeded in greatly reducing the volume of the effusion and, thus, improved the patient's clinical status. As for her prior treatment regimen, we concluded that low dose methotrexate may be a reasonable treatment alternative in selected cases of mild disease free of extraskeletal manifestations, as this patient benefited from it for two pain controlled years. Conversely, steroids are no longer recommended as a first line of treatment for ECD.

\section{Patients \#4 and 5: two cases of an atypical, painless presentation of ECD with intracranial involvement refractory to interferon-a Patient \#4}

A 62-year-old man of Yemenite descent presented with a myriad of symptoms which underwent gradual worsening over the year prior to his evaluation in our medical facility in February 2012. Among his complaints were marked fatigue and weakness, difficulty speaking, disturbance in balance and depression. His past medical history included hypertension and type II diabetes mellitus. In addition, he was diagnosed ten years prior to our evaluation with diabetes insipidus, for which he was treated with nasal desmopressin. In the process of diagnosing diabetes insipidus, the patient underwent a brain MRI which revealed multiple meningioma-like lesions as well as a finding suspected to be a demyelinating pontine lesion. Since no neurological deficits were identified, the patient remained under surveillance until one year prior to our evaluation, when he began suffering from insidious pseudo-bulbar and cerebellar syndromes. His neurological examination revealed ataxia, dysarthria, dysmetria and dysdiadochokinesia. Laboratory findings included a microcytic anemia, with a mean corpuscular volume $(\mathrm{MCV})$ of $64.8 \mathrm{fL}$. A brain MRI revealed three meningiomas, an olfactory meningioma, a frontal meningioma adjacent to the planum sphenoidale (Figure 3E) and a meningioma of the dura encasing the posterior aspect of the cavernous sinus, in the vicinity of Meckel's cave. The scan also showed unenhanced, heterogeneous 
infiltration of the pons, upper medulla and dentate nuclei (Figure 6F) as well as thickening of the infundibulum accompanied by the absence of signal from the posterior pituitary. In addition, similar to patient \#2, this patient exhibited a pattern of multiple punctate hypointensities involving the basal ganglia in SWI sequence (Figure 3D). These accumulated findings raised the possibility of a histiocytic disorder and, thus, prompted a PET/CT scan. The whole body PET/CT scan showed increased symmetric bilateral tracer uptake in the bones of the lower limbs. These bones demonstrated a patchy pattern of mixed lytic and sclerotic lesions. On CT, an abnormal appearance of the kidneys was noted and interpreted as infiltration of soft tissue into the region of the renal pelvises. Two biopsies were obtained from the tibial bones. The first bone marrow biopsy demonstrated a normocellular trilineage marrow with no evidence of histiocytosis. Only the second biopsy revealed fibrotic bone marrow lacking hematopoietic cells with clusters of CD68(+), foam cells as well as a mild to moderate mononuclear infiltrate. Several multi-nucleated giant cells were noted. Stains for CD1a and S-100 were negative. These findings were consistent with ECD. Following his diagnosis in May 2012, the patient began treatment with interferon- $\alpha$ at dosages of 1 to 3 million IU three times weekly. Despite the low dosages, this treatment was poorly tolerated. Over the 15 months period since his diagnosis was established, the patient's disease progressed indolently. Shortly after, his neurological manifestations began deteriorating rapidly. In parallel, his performance status declined markedly, he became bedridden and succumbed to his disease three months after, an overall 18 months following his diagnosis.

\section{Patient \#5}

A 53-year-old man of Libyan descent sought medical attention in November 2012 due to deterioration in his walking stability as well as slowing of his speech. Apparently, these symptoms slowly progressed over a period of approximately 18 months prior to this patient's presentation. Upon a detailed history, the patient disclosed suffering from polyuria and polydipsia for the last 7.5 years. A prior medical investigation aimed at identifying the cause of these symptoms was concluded as non diagnostic. His neurological examination revealed dysarthria, dysmetria, gait instability and a multidirectional gaze evoked nystagmus. Also, decreased left flank muscle tone and lower limb hyporeflexia were noted. A fundus examination was unremarkable. Aside from a mild normocytic anemia (hemoglobin: $12.4 \mathrm{mg} / \mathrm{dL}, \mathrm{MCV}: 86.6 \mathrm{fL}$ ), other laboratory studies, including a lumbar puncture, were without significant findings. Laboratory studies aimed at identifying viral serologies and paraneoplastic antibodies were negative. The conjunction of this patient's cerebellar syndrome, polyuria and polydipsia raised a suspicion of a histiocytic disorder. A ${ }^{99 \mathrm{~m}} \mathrm{Tc}$ bone scintigraphy study was conducted and revealed bilateral, abnormally increased tracer uptake in the distal femurs and both proximal and distal tibiae (Figure 1D). A brain MRI uncovered several abnormal findings, including a pontine lesion, mild cerebellar atrophy, absence of the posterior pituitary and a parietal parasagittal extra-axial lesion $23 \mathrm{~mm}$ in diameter, consistent with a meningioma. A whole body PET/CT scan was conducted and disclosed an increased tracer uptake in the pons, as well as the femurs and tibiae. The PET findings in the long bones correlated well with osteosclerosis as seen on CT and with the areas accentuated on the previous ${ }^{99 \mathrm{~m}} \mathrm{Tc}$ bone scintigraphy study. A biopsy from the tibial bone marrow was performed. Microscopic examination of the specimen revealed thickened, irregular bony trabeculae with numerous cement lines, insinuating increased cellular turnover. The marrow itself was found to be diffusely fibrotic with a small amount of residual fat tissue and numerous macrophages which carry a CD68 (+), CD1a(-), S-100(-) immunohistochemical profile. Langerhans cells and hematopoietic cells were not observed. This picture was consistent with bone marrow involvement of ECD. Following diagnosis in April 2013, the patient was tested for the V600E BRAF mutation and was found to be negative. Steroids were introduced as a first line treatment and later combined with vinblastine $\left(6 \mathrm{mg} / \mathrm{m}^{2} /\right.$ week $)$ as a steroid sparing agent. This treatment was administered for five months and subsequently ceased due to progressive neurological deterioration. Second line treatment with the pegylated form of interferon- $\alpha$ (135 $\mu \mathrm{g} /$ week) was administered for two months yet failed to halt this patient's neurological deterioration. Ultimately, the patient initiated treatment with cladribine IV $(0.14 \mathrm{mg} /$ $\mathrm{kg}$ /day for five consecutive days, every four weeks). Following four cycles of treatment a mild degree of radiological improvement was noted on brain MRI. Nevertheless, no clinical improvement was noted, neurological or otherwise.

\section{Patients \#4 and 5 - clinical analyses}

In these patients, aside from their longstanding diabetes insipidus, a well-known preceding sign of ECD, the initial investigations eliciting symptoms were purely neurological, primarily cerebellar in nature, without any involvement of bone pain. In both cases, a working diagnosis of a possible histiocytic disorder was raised due to a high index of suspicion, based on the clinical presentation, longstanding diabetes insipidus and on the findings of the brain MRI studies. These two patients exhibited a rather interesting phenotype of ECD, restricted primarily to the skeleton and central nervous system. Intracranially, both suffered from meningiomas and involvement of the ponto-cerebellar region. Nevertheless, a radiological subclinical focus of disease was apparent only in the 
retroperitoneum of patient \#4. In terms of response to treatment, these patients exhibited a comparable response pattern as well as a suboptimal outcome. It is likely that higher dose interferon- $\alpha$ regimens may be necessary in ECD patients with severe CNS involvement, as previously documented by Hervier et al. [56].

\section{Results}

Seven patients (five men and two women) with biopsy proven ECD were recruited from six medical centers in Israel. The median age at the time of presentation was 53 years (range: 39 to 62 years). The median follow-up time was 36 months (range: 1 to 72 months). Six of the seven patients (86\%) suffered from diabetes insipidus that preceded the onset of investigation eliciting symptoms by a median time of 87 months (range: 9 to 144 months).

The different presenting symptoms included bone pain in $43 \%$ (three of seven) of the patients. This pain ranged from mild (one patient) to severe (two patients). The patient who presented with mild bone pain originally sought medical attention for relapsing remitting skin lesions in outpatient settings. An atypical, painless presentation characterized $43 \%$ (three of seven) of the patients, who presented with worsening neurological symptoms primarily of cerebellar nature (two patients) or with renovascular hypertension (one patient). One patient (14\%) presented in the setting of an acute abdomen due to perforation of his appendix by histiocytic infiltrate. These different symptoms were accompanied by constitutional symptoms, such as fever, malaise and fatigue in all of the patients. Episodes of increased intracranial pressure notable by papilledema were evident in $57 \%$ (four of seven) of the patients. Preliminary complete blood counts identified a microcytic anemia in 57\% (four of seven) of the patients, elevated levels of CRP in $43 \%$ (three of seven) and increased erythrocyte sedimentation rate in $28.5 \%$ (two of seven).

Bone involvement was radiologically obvious in all of the patients although bone pain ultimately affected only $57 \%$ (four of seven) of the patients. The bone lesions were mostly of mixed lytic-sclerotic nature. In addition, $57 \%$ (four of seven) of the patients suffered from CNS involvements of the disease associated with emerging neurological symptoms. These intracranial involvements included mostly lesions of the pons and cerebellum, but also lesions of the cerebral hemispheres, venous sinuses and meninges. The various clinical manifestations attributed to these lesions were ataxia, dysarthria, dysmetria, dysdiadochokinesia and disturbance of balance. Retroorbital lesions caused exophthalmos in 43\% (three of seven) of the patients. A 'hairy kidney' appearance on CT was identified in $71 \%$ (five of seven) of the patients. However, renal function was preserved in all of the patients. Patient \#1 exhibited the worst renal involvement, with severe hydronephrosis and marked thinning of the cortex of the left kidney as well as compression of the right kidney by an FDG uptaking mass on a PET/CT scan. Skin lesions were noted in 57\% (four of seven) of the patients. These were periorbital yellowish xanthelasma like lesions (three patients) and up to $8 \mathrm{~mm}$ in diameter nodules of yellow-red color (one patient). Pulmonary involvement was evident in $57 \%$ (four of seven) of the patients. Two suffered from pleural effusions and the other two exhibited mild thickening of the interlobular septae on CT. The mediastinum, heart and great vessels were involved in $43 \%$ (three of seven) of the patients. One example of cardiovascular involvement was found in patient \#3 who exhibited encasement of the mediastinum and great vessels, lesions of the right atrium and recurrent pericardial effusions which responded to treatment with infliximab. Novel ophthalmological findings were identified in patient \#1, who exhibited an infiltration pattern of the sub-choroidal layer on fundoscopy.

In order to confirm the diagnosis, an average count of 1.7 separate biopsies was required (range: one to three biopsy sites), with a positive biopsy obtained from a long bone source in 57\% (four of seven) of the patients. Fifty percent of the patients tested for the V600E BRAF mutation (three of six) were found to harbor this particular mutation. The different therapeutic agents used were steroids, interferon- $\alpha$, cladribine, vinblastine, methotrexate, anakinra, infliximab and vemurafenib. Benefit from treatment was considered as either normalization of the constitutional symptoms, clinical improvement correlating with the relevant sites of involvement, radiological evidence of lesion regression or a combination of these three parameters. Interferon- $\alpha$ was beneficial in $50 \%$ (three of six) of the patients treated. It is noteworthy that the peri-renal, cardiovascular and intracranial involvements proved to be rather refractory to treatment with interferon- $\alpha$ at dosages below $6 \times 10^{6}$ IU X 3 times weekly. Additionally, notable neurological improvement was observed following treatment with vemurafenib in a BRAF V600E positive patient. Regression of a substantial pericardial effusion was observed following treatment with infliximab and moderate reduction in the compression of intracranial perivascular sheathing (evident by improved perfusion and imaging) was achieved after treatment with cladribine.

\section{Discussion}

In the past three years, the constantly growing clinical awareness of medical professionals has globally promoted several substantial achievements in the evolution of ECD. First, the rate at which patients are being diagnosed has risen dramatically. Patients are being diagnosed much earlier in the course of their disease. We now witness subclinical, nearly asymptomatic ECD patients. Thus, new 
dilemmas are discussed regarding the potential benefits and risks of early medical interventions. Second, annual ECD conferences are being held, promoting novel research initiatives as well as the emergence of the first edition of consensus guidelines [53].

Nevertheless, the proper diagnosis and management of an ECD patient remains a challenge. From our clinical experience with seven patients, several key issues should be addressed in the management of such patients. In terms of diagnosis, as previously reported $[81,38]$, diabetes insipidus of an unexplained etiology may precede the onset of investigation eliciting symptoms by as many as twelve years. Most peculiarly, the various anatomical disruptions of the hypothalamic - pituitary regions that could explain such a phenomenon appear on MRI, if at all, months to years following diagnosis. This gap of time suggests that the initial manifestations of ECD could indolently progress from microscopic involvement which generates a functional disturbance of the posterior pituitary. Ultimately, this process may become evident on MRI as absence of the high signal intensity of the posterior pituitary on T1 weighted images or as thickening of the pituitary stalk.

Another core issue relating to diagnosis of ECD is the investigation eliciting symptom, which is most commonly bone pain. Complaints of diffuse long bone pain of unexplained etiology in conjunction with a history of diabetes insipidus should prompt a high index of suspicion towards ECD. This suspicion may be further substantiated in the face of constitutional inflammatory signs and symptoms, such as fever, malaise and increased levels of ESR and CRP. The typical, symmetrical, bilateral appearance of increased tracer uptake involving the long bones on a ${ }^{99} \mathrm{~m}$ Tc bone scintigraphy study should prompt biopsies from high suspicion bone marrow foci for CD68(+), CD1a(-) histiocytes, a finding which finalizes the diagnosis of ECD. Additionally, a $\mathrm{PET} / \mathrm{CT}$ scan may be useful in documenting extraskeletal involvements of ECD for the purposes of follow-up or tissue acquisition. Occasionally, more than one biopsy may be needed to successfully obtain a diagnostic specimen from a focus of interest. In many cases, the bone marrow comprises a reasonable biopsy site. This is because it has proven reliable in the detection of the typical tissue architecture that characterizes ECD on pathological examinations, as well as the relative ease at which immunohistochemical dyes are applied. However, detection of the V600E BRAF mutation using PCR technology is more difficult to perform and yields less accurate data when processed from a skeletal tissue source. Conversely, favorable specimen sources for such an examination are ECD skin lesions and the infiltrated peri-renal fat that appears as a 'hairy kidney' on computed tomography.
Renal involvement is a common finding in ECD. In their paper published in 2011, Haroche et al. report from their clinical experience that $68 \%$ of their patients were found to express a 'hairy kidney' appearance on imaging studies [5]. This radiological finding is typical of peri-renal histiocytic infiltration among ECD patients. Renal involvement in ECD should be a concern for the managing physician, as peri-renal lesions may ultimately lead to a post renal obstruction causing silent loss of a single, or an apparent loss of both, kidneys [21]. Moreover, peri-renal involvement in ECD may compromise the patency of the renal arteries due to external compression, causing secondary renovascular hypertension and renal failure [82]. Thus, frequent sonographic assessments of the kidneys and ureters are advised for ECD patients alongside ureteral stenting in selected cases.

The intracranial manifestations of ECD are diverse. However, involvement of the cerebellum is frequent, particularly in the peri-dentate regions and in close proximity to the fourth ventricle. Radiologically, these lesions may be heterogeneous in nature. It is noteworthy that two of our seven patients exhibited multiple punctate hypointensities in the basal ganglia in SWI sequence. This pattern was never observed by us before in the context of ECD. Yet another novel finding was that of an ophthalmological involvement of ECD. In patient \#1, sub-choroidal lesions involving the macula densa appeared on fundoscopy of both eyes and were better visible on red free imaging produced by a blue wavelength confocal scanning laser ophthalmoscope. These findings proved to be stable on a neuro-ophthalmological follow up performed two years following their discovery. To our knowledge, this is the first report of ECD-associated retinal findings ever reported in the medical literature. This subchoroidal infiltration pattern may contribute to the understanding of the mechanisms involved in visual disturbances in ECD. Disturbances of vision in ECD are attributed to exophthalmos, increased intracranial pressure and papilledema. It is plausible that interruption of the visual fields and decreased visual acuity may originate in part due to a microscopic process involving the retina. In the case of patient \#1, the initial visual field disturbances were attributed to increased intracranial pressure while those that appeared later, were attributed to these subchoroidal lesions.

Treatment wise, it is well established that interferon- $\alpha$ should serve as the mainstay of therapy for ECD. In the past, vinblastine was administered to ECD patients as a single agent or in combination with interferon- $\alpha$ with anecdotal reports of objective response [68,83]. Vinblastine was considered primarily by analogy to the treatment of Langerhans cell histiocytosis, potentially as a means to augment the effect of interferon- $\alpha$. However, of three patients $(\# 1, \# 3, \# 5)$ treated with vinblastine, only patient 
\#1 benefited from the addition of vinblastine to high dose interferon- $\alpha$.

Recent advances in the understanding of the molecular biology underlying ECD have led to novel therapeutic approaches to this disease. The accumulated data in the literature strongly advocate that ECD is, in fact, a clonal, neoplastic disorder originating from monocytic myeloid blood components that exhibit prominent inflammatory characteristics. A majority of these clones seem to be predominantly driven by molecular elements involving the $R A S / R A F / M E K / E R K$ signal transduction pathway, such as $B R A F$ and NRAS, among others [50,84]. One particular element identified in several large series, as well as in ours, is the occurrence of the V600E BRAF mutation in approximately $50 \%$ of the patients [50]. Nevertheless, the ability to accurately detect such genetic alterations is subject to several limiting factors including adequacy of samples, accuracy of the technology used and the level of staff expertise in performing such tests. For example, Cangi et al. report they were able to detect the V600E BRAF mutation in all of the patients evaluated in their cohort using the appropriate molecular techniques [85].

The pharmacological targeting of the V600E BRAF mutation by the drug vemurafenib repeatedly yielded dramatic clinical benefit in a significant portion of patients, unparallel to that of any other agent attempted in the treatment of ECD. Evidently, this mutation should be considered as a cardinal determinant in the therapeutic roadmap planning for ECD patients. From our limited experience, we support vemurafenib as a second line treatment agent for ECD patients who tested positive for the V600E BRAF mutation and failed to respond to adequate doses of interferon- $\alpha$.

$B R A F$ negative patients should be offered the repertoire of treatment alternatives according to the severity and distribution of their disease. In our series, interferon- $\alpha$ was found to play a beneficial role in the treatment of the skeletal manifestations of ECD. However, different patients in our series responded variably to interferon- $\alpha$ in terms of the extraskeletal disease involvement sites and the degree of lesion and symptom regression. A delicate balance between toxicity and efficacy should be sought in the dosage modulation of interferon- $\alpha$, especially in patients with cardiovascular and CNS disease localizations.

\section{Patient consent}

All the patients included in this study signed a consent form permitting the use of their medical records for the purpose of this publication.

\section{Competing interests}

The authors declare that they have no competing interests.

\section{Authors' contributions}

RDM designed the study, gathered the clinical and radiological data, recruited consultants, completed the patients' workup and participated in drafting the majority of the manuscript. MMM assisted in gathering the data and participated in drafting the manuscript. AK performed the neuro-ophthalmological assessment of the patients. OA performed the neuro-radiological interpretation of the brain MRI studies of the patients. IE performed the musculoskeletal radiological evaluation of the patients. $\mathrm{RJ}$ evaluated the pathological specimens. YP, IG and ES performed the dermatological analysis and follow up of the patients. IY performed the endocrinological assessment of the patients. AG and CG performed the hematological evaluation of the patients. YS participated in the design and coordination of the study as well as oversaw the global management of the patients. All the authors participated in revising the manuscript for intellectual content. All authors read and approved the final manuscript.

\section{Acknowledgments}

We would like to thank our elaborated team of consultants, who contributed their wisdom to the project and assisted in the analyses of our seven patients. Imaging: Prof. Eli Konen, head of the diagnostic imaging and specialist in cardiovascular imaging, Sheba medical center, Dr. Yoram Segev, specialist in neuroimaging, Shaare Zedek medical center. Nuclear medicine: Prof. Einat Even-Sapir, director of the institute of nuclear medicine, Tel-Aviv Sourasky medical center. Genetics: Prof. Elon Pras, head of the Danek Gertner Institute of Human Genetics, Sheba medical center. Pathology: Prof. Iris Barshack, head of the institute of pathology, Sheba medical center. Neuro-oncology: Prof. Tali Siegal, center for Neuro-Oncology, Davidoff Institute of oncology, Rabin medical center, Prof. Alexander Lossos specialist in neuro-oncology, Hadassah medical center. Hematology: Dr. Elena Ribakovsky, specialist in hematology, Sheba medical center. Internal medicine: Prof. Yehezkel Sidi, head of internal medicine C, Sheba medical center. Ophthalmology: Dr. Michaella Goldstein, deputy head of ophthalmology department and director of retina clinic, Tel-Aviv Sourasky medical center.

This work was performed by Roei D. Mazor in partial fulfillment of the M.D. thesis requirements of the Sackler Faculty of Medicine, Tel Aviv University.

\section{Author details}

${ }^{1}$ The Zabludowicz Center for Autoimmune Diseases, Sheba Medical Center, Tel Hashomer, Israel. '2Sackler Faculty of Medicine, Tel Aviv University, Tel Aviv, Israel. ${ }^{3}$ Department of Ophthalmology, Neuro-ophthalmology Unit, Tel Aviv-Sourasky Medical Center, Tel Aviv, Israel. " Department of Radiology, Neuroradiology Unit, Tel Aviv-Sourasky Medical Center, Tel Aviv, Israel. ${ }^{5}$ Department of Diagnostic Imaging, Sheba Medical Center, Tel Aviv University, Tel Hashomer, Israel. ${ }^{6}$ Department of Pathology, University of Pittsburgh, School of Medicine and Children's Hospital, Pittsburgh, USA. ${ }^{7}$ Department of Dermatology, Tel-Aviv Sourasky Medical Center, Tel-Aviv, Israel. ${ }^{8}$ Institute of Endocrinology, Metabolism and Hypertension, Tel Aviv-Sourasky Medical Center, Tel Aviv, Israel. 'Department of Hematology, Hadassah University Hospital, Jerusalem, Israel. ${ }^{10}$ Department of Hematology, Shaare Zedek Medical Center, Jerusalem, Israel.

Received: 18 August 2014 Accepted: 3 November 2014 Rin

\section{References}

1. Mazor RD, Manevich-Mazor M, Shoenfeld Y: Erdheim-Chester Disease: a comprehensive review of the literature. Orphanet J Rare Dis 2013, 8:137.

2. Munoz J, Janku F, Cohen PR, Kurzrock R: Erdheim-Chester disease: characteristics and management. Mayo Clin Proc 2014, 89:985-996.

3. Allen CE, McClain KL: Erdheim-Chester: beyond the lesion. Blood 2011, 117:2745-2746.

4. Wilejto M, Abla O: Langerhans cell histiocytosis and Erdheim-Chester disease. Curr Opin Rheumatol 2012, 24:90-96.

5. Haroche J, Arnaud L, Amoura Z: Erdheim-Chester disease. Curr Opin Rheumatol 2012, 24:53-59.

6. Dion E, Graef C, Miquel A, Haroche J, Wechsler B, Amoura Z, Zeitoun D, Grenier PA, Piette JC, Laredo JD: Bone involvement in Erdheim-Chester disease: imaging findings including periostitis and partial epiphyseal involvement. Radiology 2006, 238:632-639. 
7. Drier A, Haroche J, Savatovsky J, Godeneche G, Dormont D, Chiras J, Amoura Z, Bonneville F: Cerebral, facial, and orbital involvement in Erdheim-Chester disease: CT and MR imaging findings. Radiology 2010, 255:586-594.

8. Oweity T, Scheithauer BW, Ching HS, Lei C, Wong KP: Multiple system Erdheim-Chester disease with massive hypothalamic-sellar involvement and hypopituitarism. J Neurosurg 2002, 96:344-351.

9. Carpinteri R, Patelli I, Casanueva FF, Giustina A: Pituitary tumours: inflammatory and granulomatous expansive lesions of the pituitary. Best Pract Res Clin Endocrinol Metab 2009, 23:639-650.

10. Vital C, Bioulac-Sage P, Tison F, Rivel J, Begueret H, Gomez C, LeauteLabreze C, Diard F, Vital A: Brain stem infiltration by mixed Langerhans cell histiocytosis and Chester-Erdheim disease: more than just an isolated case? Clin Exp Pathol 1999, 47:71-76.

11. Sedrak P, Ketonen L, Hou P, Guha-Thakurta N, Williams MD, Kurzrock R, Debnam JM: Erdheim-Chester disease of the central nervous system: new manifestations of a rare disease. AJNR Am J Neuroradiol 2011, 32:2126-2131

12. Haroche J, Cluzel P, Toledano D, Montalescot G, Touitou D, Grenier PA, Piette JC, Amoura Z: Images in cardiovascular medicine. Cardiac involvement in Erdheim-Chester disease: magnetic resonance and computed tomographic scan imaging in a monocentric series of 37 patients. Circulation 2009, 119:e597-e598.

13. Killu AM, Liang JJ, Jaffe AS: Erdheim-Chester disease with cardiac involvement successfully treated with anakinra. Int J Cardiol 2013, 167:e115-117.

14. Monti L, Haroche J, Sciarra A, Balzarini L, Fiamengo B, Amoura Z, Graziani G: Interferon-alpha in cardiac Erdheim-Chester disease. J Am Coll Cardiol 2011, 58:2695

15. Merli E, Savelli F, Lovato L, Zompatori M: Cardiac involvement in ErdheimChester disease: echocardiographic appearance and value of cardiac MRI. Eur Heart J Cardiovasc Imaging 2012, 13:198.

16. Arnaud L, Pierre I, Beigelman-Aubry C, Capron F, Brun AL, Rigolet A, Girerd X, Weber N, Piette JC, Grenier PA, Amoura Z, Haroche J: Pulmonary involvement in Erdheim-Chester disease: a single-center study of thirty-four patients and a review of the literature. Arthritis Rheum 2010, 62:3504-3512.

17. Yahng SA, Kang HH, Kim SK, Lee SH, Moon HS, Lee BY, Kim HS, Seo EJ: Erdheim-Chester disease with lung involvement mimicking pulmonary lymphangitic carcinomatosis. Am J Med Sci 2009, 337:302-304.

18. Protopapadakis C, Antoniou KM, Nicholson AG, Voloudaki A, Tzanakis N, Karantanas A, Siafakas NM: Erdheim-Chester disease: pulmonary presentation in a case with advanced systemic involvement. Respiration 2009, 77:337-340.

19. Yelfimov DA, Lightner DJ, Tollefson MK: Urologic manifestations of Erdheim-Chester disease. Urology 2014, 84:218-221.

20. Wimpissinger TF, Schernthaner G, Feichtinger H, Stackl W: Compression of kidneys in Erdheim-Chester disease of retroperitoneum: open surgical approach. Urology 2005, 65:798.

21. Sanchez JE, Mora C, Macia M, Navarro JF: Erdheim-Chester disease as cause of end-stage renal failure: a case report and review of the literature. Int Urol Nephrol 2010, 42:1107-1112.

22. Lee HJ, Lee KY, Shin DY, Lee YG, Choi SY, Moon KC, Han IK, Kim TM: A case of erdheim-chester disease with asymptomatic renal involvement. Cancer Res Treat 2012, 44:146-150.

23. Heller MT, Haarer KA, Thomas E, Thaete FL: Neoplastic and proliferative disorders of the perinephric space. Clin Radiol 2012, 67:e31-e41.

24. Haroche J, Amoura Z, Touraine P, Seilhean D, Graef C, Birmele B, Wechsler B, Cluzel P, Grenier PA, Piette JC: Bilateral adrenal infiltration in Erdheim-Chester disease. Report of seven cases and literature review. $J$ Clin Endocrinol Metab 2007, 92:2007-2012

25. Skinner M, Briant M, Morgan MB: Erdheim-Chester disease: a histiocytic disorder more than skin deep. Am J Dermatopathol 2011, 33:e24-e26.

26. Volpicelli ER, Doyle L, Annes JP, Murray MF, Jacobsen E, Murphy GF, Saavedra AP: Erdheim-Chester disease presenting with cutaneous involvement: a case report and literature review. J Cutan Pathol 2011, 38:280-285.

27. Opie KM, Kaye J, Vinciullo C: Erdheim-Chester disease. Australas J Dermatol 2003, 44:194-198.

28. Detlefsen S, Fagerberg CR, Ousager LB, Lindebjerg J, Marcussen N, Nathan T, Sørensen FB: Histiocytic disorders of the gastrointestinal tract. Hum Pathol 2013, 44:683-696.
29. Ivan D, Neto A, Lemos L, Gupta A: Erdheim-Chester disease: a unique presentation with liver involvement and vertebral osteolytic lesions. Arch Pathol Lab Med 2003, 127:e337-e339.

30. Gundling F, Nerlich A, Heitland WU, Schepp W: Biliary manifestation of Erdheim-Chester disease mimicking Klatskin's carcinoma. Am J Gastroenterol 2007, 102:452-454

31. Pan A, Doyle T, Schlup M, Lubcke R, Schultz M: Unusual manifestation of Erdheim-Chester disease. BMC Gastroenterol 2011, 11:77.

32. Tan AP, Tan LK, Choo IH: Erdheim-Chester disease involving breast and muscle: imaging findings. AJR Am J Roentgenol 1995, 164:1115-1117.

33. Barnes PJ, Foyle A, Hache KA, Langley RG, Burrell S, Juskevicius R: ErdheimChester disease of the breast: a case report and review of the literature. Breast J 2005, 11:462-467.

34. Provenzano E, Barter SJ, Wright PA, Forouhi P, Allibone R, Ellis IO: Erdheimchester disease presenting as bilateral clinically malignant breast masses. Am J Surg Pathol 2010, 34:584-588.

35. Ambrosini V, Savelli F, Merli E, Zompatori M, Nanni C, Allegri V, Fanti S: F-18 FDG PET/CT detects muscle involvement in Erdheim-Chester disease. Clin Nucl Med 2012, 37:196-197.

36. Sheu SY, Wenzel RR, Kersting C, Merten R, Otterbach F, Schmid KW: Erdheim-Chester disease: case report with multisystemic manifestations including testes, thyroid, and lymph nodes, and a review of literature. J Clin Pathol 2004, 57:1225-1228.

37. Rao RN, Chang CC, Uysal N, Presberg K, Shidham VB, Tomashefski JF Jr: Fulminant multisystem non-langerhans cell histiocytic proliferation with hemophagocytosis: a variant form of Erdheim-Chester disease. Arch Pathol Lab Med 2005, 129:e39-e43.

38. Arnaud L, Hervier B, Neel A, Hamidou MA, Kahn JE, Wechsler B, Pérez-Pastor G, Blomberg B, Fuzibet JG, Dubourguet F, Marinho A, Magnette C, Noel V, Pavic M, Casper J, Beucher AB, Costedoat-Chalumeau N, Aaron L, Salvatierra J, Graux C, Cacoub P, Delcey V, Dechant C, Bindi P, Herbaut C, Graziani G, Amoura Z, Haroche J: CNS involvement and treatment with interferonalpha are independent prognostic factors in Erdheim-Chester disease: a multicenter survival analysis of 53 patients. Blood 2011, 117:2778-2782.

39. Haroche J, Amoura Z, Dion E, Wechsler B, Costedoat-Chalumeau N, Cacoub $P$, Isnard R, Généreau T, Wechsler J, Weber N, Graef C, Cluzel P, Grenier P, Piette JC: Cardiovascular involvement, an overlooked feature of ErdheimChester disease: report of 6 new cases and a literature review. Medicine (Baltimore) 2004, 83:371-392.

40. Tran TA, Pariente D, Lecron JC, Delwail A, Taoufik Y, Meinzer U: Treatment of pediatric Erdheim-Chester disease with interleukin-1-targeting drugs Arthritis Rheum 2011, 63:4031-4032.

41. Tran TA, Fabre M, Pariente D, Craiu I, Haroche J, Charlotte F, Eid P, Durrbach A, Taoufik Y, Kone-Paut I: Erdheim-Chester disease in childhood: a challenging diagnosis and treatment. J Pediatr Hematol Oncol 2009, 31:782-786.

42. Kumandas S, Kurtsoy A, Canoz O, Patiroglu T, Yikilmaz A, Per H: Erdheim Chester disease: cerebral involvement in childhood. Brain Dev 2007 29:227-230.

43. Joo CU, Go YS, Kim IH, Kim CS, Lee SY: Erdheim-Chester disease in a child with MR imaging showing regression of marrow changes. Skeletal Radiol 2005, 34:299-302.

44. Clerico A, Ragni G, Cappelli C, Schiavetti A, Gonfiantini M, Uccini S: Erdheim-Chester disease in a child. Med Pediatr Oncol 2003, 41:575-577.

45. Tsai JW, Tsou JH, Hung LY, Wu HB, Chang KC: Combined Erdheim-Chester disease and Langerhans cell histiocytosis of skin are both monoclonal: a rare case with human androgen-receptor gene analysis. J Am Acad Dermatol 2010, 63:284-291.

46. Al-Quran S, Reith J, Bradley J, Rimsza L: Erdheim-Chester disease: case report, PCR-based analysis of clonality, and review of literature. Mod Pathol 2002, 15:666-672.

47. Chetritt J, Paradis V, Dargere D, Adle-Biassette H, Maurage CA, Mussini JM, Vital A, Wechsler J, Bedossa P: Chester-Erdheim disease: a neoplastic disorder. Hum Pathol 1999, 30:1093-1096.

48. Vencio EF, Jenkins RB, Schiller JL, Huynh TV, Wenger DD, Inwards $C Y$, Oliveira AM: Clonal cytogenetic abnormalities in Erdheim-Chester disease. Am J Surg Pathol 2007, 31:319-321.

49. Arnaud L, Gorochov G, Charlotte F, Lvovschi V, Parizot C, Larsen M, GhillaniDalbin P, Hervier B, Kahn JE, Deback C, Musset L, Amoura Z, Haroche J: Systemic perturbation of cytokine and chemokine networks in Erdheim-Chester disease: a single-center series of 37 patients. Blood 2011, 117:2783-2790. 
50. Haroche J, Charlotte F, Arnaud L, von Deimling A, Helias-Rodzewicz Z, Hervier B, Cohen-Aubart F, Launay D, Lesot A, Mokhtari K, Canioni D, Galmiche L, Rose C, Schmalzing M, Croockewit S, Kambouchner M, Copin MC, Fraitag S, Sahm F, Brousse N, Amoura Z, Donadieu J, Emile JF: High prevalence of BRAF V600E mutations in Erdheim-Chester disease but not in other non-Langerhans cell histiocytoses. Blood 2012, 120:2700-2703.

51. Berres ML, Allen CE, Merad M: Pathological consequence of misguided dendritic cell differentiation in histiocytic diseases. Adv Immunol 2013, 120:127-161.

52. Mazor RD, Manevich-Mazor M, Shoenfeld Y: Strategies and treatment alternatives in the management of Erdheim-Chester disease. Expert Opinion Orphan Drugs 2013, 1:891-899.

53. Diamond EL, Dagna L, Hyman DM, Cavalli G, Janku F, Estrada-Veras J, Ferrarini M, Abdel-Wahab O, Heaney ML, Scheel PJ, Feeley NK, Ferrero E, McClain KL, Vaglio A, Colby T, Arnaud L, Haroche J: Consensus guidelines for the diagnosis and clinical management of Erdheim-Chester disease. Blood 2014, 124:483-492.

54. Braiteh F, Boxrud C, Esmaeli B, Kurzrock R: Successful treatment of Erdheim-Chester disease, a non-Langerhans-cell histiocytosis, with interferon-alpha. Blood 2005, 106:2992-2994.

55. Haroche J, Amoura Z, Trad SG, Wechsler B, Cluzel P, Grenier PA, Piette JC: Variability in the efficacy of interferon-alpha in Erdheim-Chester disease by patient and site of involvement: results in eight patients. Arthritis Rheum 2006, 54:3330-3336

56. Hervier B, Arnaud L, Charlotte F, Wechsler B, Piette JC, Amoura Z, Haroche J: Treatment of Erdheim-Chester disease with long-term high-dose interferon-alpha. Semin Arthritis Rheum 2012, 41:907-913.

57. Aouba A, Georgin-Lavialle S, Pagnoux C, Martin Silva N, Renand A, GalateauSalle F, Le Toquin S, Bensadoun H, Larousserie F, Silvera S, Provost N, Candon S, Seror R, de Menthon M, Hermine O, Guillevin L, Bienvenu B: Rationale and efficacy of interleukin-1 targeting in Erdheim-Chester disease. Blood 2010, 116:4070-4076.

58. Aubert O, Aouba A, Deshayes S, Georgin-Lavialle S, Rieu P, Hermine O: Favorable radiological outcome of skeletal Erdheim-Chester disease involvement with anakinra. Joint Bone Spine 2013, 80:206-207.

59. Adam Z, Szturz P, Buckova P, Cervinkova I, Koukalova R, Rehak Z, Krejčí M, Pour L, Zahradová L, Hájek R, Král Z, Mayer J: Interleukin-1 receptor blockade with anakinra provided cessation of fatigue, reduction in inflammation markers and regression of retroperitoneal fibrosis in a patient with Erdheim-Chester disease - case study and a review of literature. Vnitr Lek 2012, 58:313-318. In Czech.

60. Dagna L, Corti A, Langheim S, Guglielmi B, De Cobelli F, Doglioni C, Fragasso G, Sabbadini MG, Ferrarini M: Tumor necrosis factor alpha as a master regulator of inflammation in Erdheim-Chester disease: rationale for the treatment of patients with infliximab. J Clin Oncol 2012, 30:e286-e290.

61. Haroche J, Cohen-Aubart F, Emile JF, Arnaud L, Maksud P, Charlotte F, Cluzel P, Drier A, Hervier B, Benameur N, Besnard S, Donadieu J, Amoura Z: Dramatic efficacy of vemurafenib in both multisystemic and refractory Erdheim-Chester disease and Langerhans cell histiocytosis harboring the BRAF V600E mutation. Blood 2013, 121:1495-1500.

62. Blombery P, Wong SQ, Lade S, Prince HM: Erdheim-Chester disease harboring the BRAF V600E mutation. J Clin Oncol 2012, 30:e331-e332.

63. Adam Z, Szturz P, Pour L, Krejci M, Zahradova L, Tomiska M, Král Z, Koukalová R, Rehák Z, Mayer J: Cladribine is highly effective in the treatment of Langerhans cell histiocytosis and rare histiocytic disorders of the juvenile xanthogranuloma group. Vnitr Lek 2012, 58:455-465. In Czech.

64. Adam Z, Sprlakova A, Rehak Z, Koukalova R, Szturz P, Krejci M, Pour L, Zahradová L, Cervinek L, Kren L, Moulis M, Hermanová M, Mechl M, Prásek J, Hájek R, Král Z, Mayer J: Partial regression of CNS lesions of ErdheimChester disease after treatment with 2-chlorodeoxadenosine and their full remission following treatment with lenalidomide. Klin Onkol 2011, 24:367-381. In Czech.

65. Adam Z, Koukalova R, Sprlakova A, Rehak Z, Cervinek L, Szturz P, Krejcí M, Pour L, Zahradová L, Moulis M, Prásek J, Chaloupka R, Hájek R, Mayer J: Successful treatment of Erdheim-Chester disease by 2chlorodeoxyadenosine-based chemotherapy. Two case studies and a literature review. Vnitr Lek 2011, 57:576-589. In Czech.

66. Myra C, Sloper L, Tighe PJ, Mclntosh RS, Stevens SE, Gregson RH, Sokal M, Haynes AP, Powell RJ: Treatment of Erdheim-Chester disease with cladribine: a rational approach. $\mathrm{Br} J$ Ophthalmol 2004, 88:844-847.
67. Smith JR, Rosenbaum JT: A role for methotrexate in the management of non-infectious orbital inflammatory disease. Br J Ophthalmol 2001, 85:1220-1224.

68. Jendro MC, Zeidler H, Rosenthal H, Haller H, Schwarz A: Improvement of Erdheim-Chester disease in two patients by sequential treatment with vinblastine and mycophenolate mofetil. Clin Rheumatol 2004, 23:52-56.

69. Broccoli A, Stefoni V, Faccioli L, Agostinelli C, Spinardi L, Pastore Trossello M, Zinzani PL: Bilateral orbital Erdheim-Chester disease treated with 12 weekly administrations of VNCOP-B chemotherapy: a case report and a review of literature. Rheumatol Int 2012, 32:2209-2213.

70. Badzek S, Misir-Krpan A, Krajina Z, Radman I, Stern-Padovan R, Dotlic S: Erdheim-Chester disease and concomitant tuberculosis successfully treated with chemotherapy and long-term steroids. Coll Antropol 2007 31:621-623

71. Franco P, Filippi AR, Ciammella P, Botticella A, Namysl-Kaletka A, Ricardi U: Polyostotic sclerosing histiocytosis (Erdheim-Chester disease) treated with combined vertebroplasty and radiation therapy. Tumori 2010, 96:633-636

72. Matsui K, Nagata Y, Hiraoka M: Radiotherapy for Erdheim-Chester disease. Int J Clin Oncol 2007, 12:238-241.

73. Miller RC, Villa S, Kamer S, Pasquier D, Poortmans P, Micke O, Call TG: Palliative treatment of Erdheim-Chester disease with radiotherapy: a Rare Cancer Network study. Radiother Oncol 2006, 80:323-326.

74. Mascalchi M, Nencini P, Nistri M, Sarti C, Santoni R: Failure of radiation therapy for brain involvement in Erdheim Chester disease. J Neurooncol 2002, 59:169-172.

75. Veyssier-Belot C, Cacoub P, Caparros-Lefebvre D, Wechsler J, Brun B, Remy M, Wallaert B, Petit H, Grimaldi A, Wechsler B, Godeau P: Erdheim-Chester disease. Clinical and radiologic characteristics of 59 cases. Medicine (Baltimore) 1996, 75:157-169.

76. Mossetti G, Rendina D, Numis FG, Somma P, Postiglione L, Nunziata V: Biochemical markers of bone turnover, serum levels of interleukin-6/ interleukin- 6 soluble receptor and bisphosphonate treatment in Erdheim-Chester disease. Clin Exp Rheumatol 2003, 21:232-236.

77. Eyigor S, Kirazli Y, Memis A, Basdemir G: Erdheim-Chester disease: the effect of bisphosphonate treatment-a case report. Arch Phys Med Rehabil 2005, 86:1053-1057.

78. Srikulmontree T, Massey HD, Roberts WN: Treatment of skeletal ErdheimChester disease with zoledronic acid: case report and proposed mechanisms of action. Rheumatol Int 2007, 27:303-307.

79. Boissel N, Wechsler B, Leblond V: Treatment of refractory Erdheim-Chester disease with double autologous hematopoietic stem-cell transplantation. Ann Intern Med 2001, 135:844-845.

80. Gaspar N, Boudou P, Haroche J, Wechsler B, Van Den Neste E, Hoang-Xuan K, Amoura Z, Guillevin R, Savatovski J, Azar N, Piette JC, Leblond V: High-dose chemotherapy followed by autologous hematopoietic stem cell transplantation for adult histiocytic disorders with central nervous system involvement. Haematologica 2006, 91:1121-1125.

81. Cavalli G, Guglielmi B, Berti A, Campochiaro C, Sabbadini MG, Dagna L: The multifaceted clinical presentations and manifestations of ErdheimChester disease: comprehensive review of the literature and of 10 new cases. Ann Rheum Dis 2013, 72:1691-1695.

82. O'Rourke R, Wong DC, Fleming S, Walker D: Erdheim-Chester disease: a rare cause of acute renal failure. Australas Radio/ 2007, 51:Spec No.B48-B51.

83. Jeon IS, Lee SS, Lee MK: Chemotherapy and interferon-alpha treatment of Erdheim-Chester disease. Pediatr Blood Cancer 2010, 55:745-747.

84. Diamond EL, Abdel-Wahab O, Pentsova E, Borsu L, Chiu A, Teruya-Feldstein J, Hyman DM, Rosenblum M: Detection of an NRAS mutation in ErdheimChester disease. Blood 2013, 122:1089-1091.

85. Cangi MG, Biavasco R, Cavalli G, Grassini G, Dal-Cin E, Campochiaro C, Guglielmi B, Berti A, Lampasona V, von Deimling A, Sabbadini MG, Ferrarini M, Doglioni C, Dagna L: BRAFV600E-mutation is invariably present and associated to oncogene-induced senescence in Erdheim-Chester disease. Ann Rheum Dis 2014. doi:10.1136/annrheumdis-2013-204924.

\section{doi:10.1186/s12916-014-0221-3}

Cite this article as: Mazor et al.: Clinical considerations and key issues in the management of patients with Erdheim-Chester Disease: a seven case series. BMC Medicine 2014 12:221. 